\title{
FOOD SYSTEM PPPS: CAN THEY ADVANCE PUBLIC HEALTH AND BUSINESS GOALS AT THE SAME TIME?
}

\section{ANALYSIS AND IDEAS FOR MOVING FORWARD}

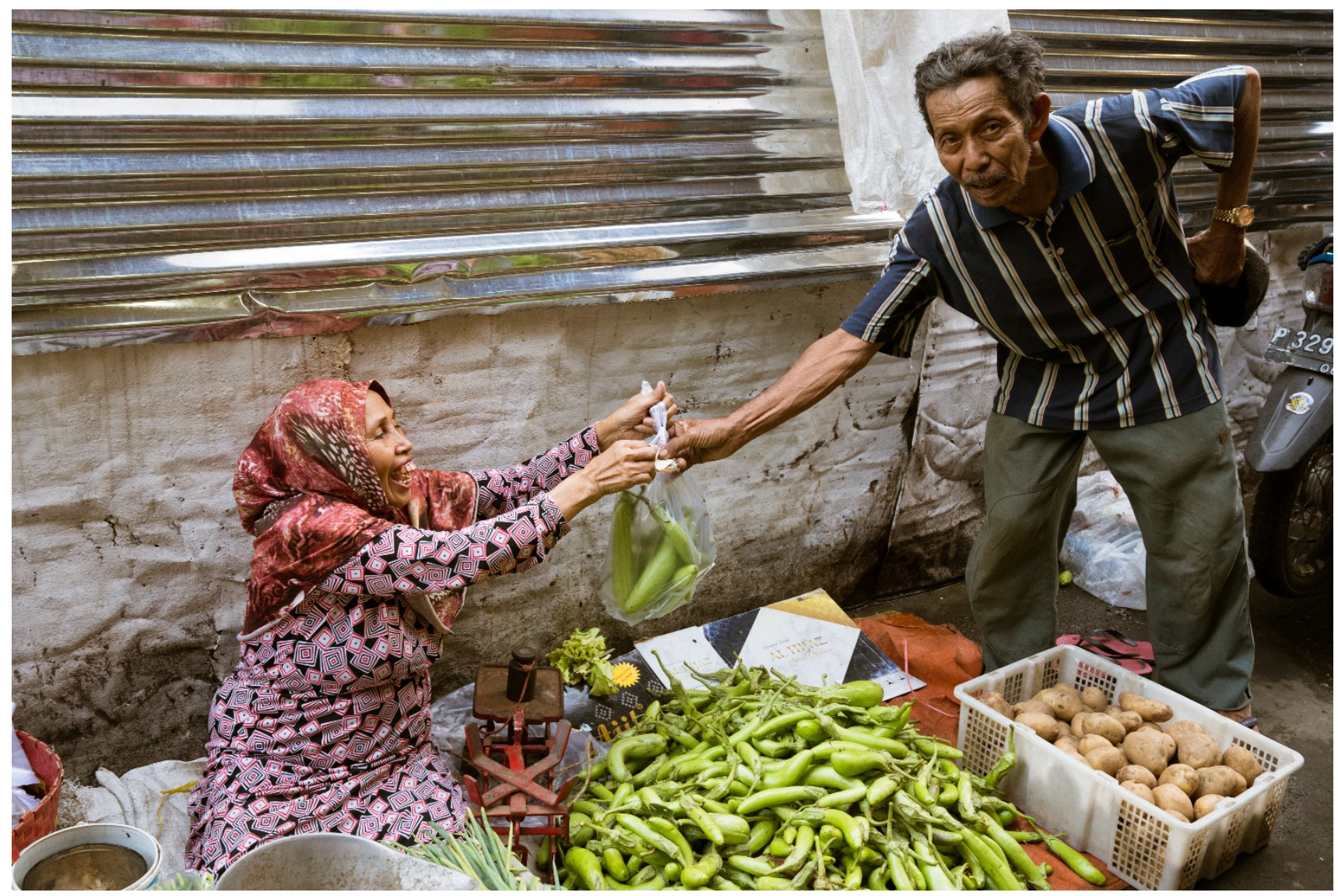

GAIN Discussion Paper $n^{\circ} 6$

May, 2020

Jessica Fanzo, Yusra Ribhi Shawar, Tara Shyam, Shreya Das, and Jeremy Shiffman

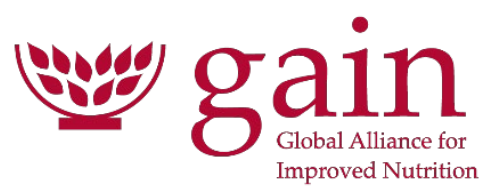




\section{ABOUT GAIN}

The Global Alliance for Improved Nutrition (GAIN) is a Swiss-based foundation launched the UN in 2002 to tackle the human suffering caused by malnutrition. Working with governments, businesses and civil society, we aim to transform food systems so that they deliver more nutritious food for all people, especially the most vulnerable.

\section{Recommended citation}

Fanzo J, Shawar, YR, Shyam, T, Das, S and Shiffman, J. Food System PPPs: Can they Advance Public Health and Business Goals at the Same Time? Analysis and Ideas for Moving Forward. Global Alliance for Improved Nutrition (GAIN). Discussion Paper \#6. Geneva, Switzerland, 2020. DOI:

https://doi.org/10.36072/dp.6

\section{() The Global Alliance for Improved Nutrition (GAIN)}

This work is available under the Creative Commons Attribution-Non-Commercial-Share Alike 4.0 IGO licence (CC BY-NC-SA 4.0 IGO; https://creativecommons.org/licenses/by-nc-sa/4.0/). Under the terms of this licence, you may copy, redistribute and adapt the work for non-commercial purposes, provided the work is appropriately cited, as indicated below. In any use of this work, there should be no suggestion that GAIN endorses any specific organisation, products or services. The use of the GAIN logo is not permitted. If you adapt the work, then you must license your work under the same or equivalent Creative Commons license. The contribution of third parties do not necessarily represent the view or opinion of GAIN.

\section{Acknowledgements}

This work was commissioned to the authors by the GAIN as part of the Making Markets Work to Improve the Consumption of Safe and Nutritious Foods programme, which is supported by Bill \& Melinda Gates Foundation, Federal Ministry for Economic Cooperation and Development (Germany), International Development Research Centre (Canada), Irish Aid, Ministry of Foreign Affairs of the Netherlands, Swiss Agency for Development and Cooperation. The authors are affiliated with the Paul $\mathrm{H}$. Nitze School of Advanced International Studies, The Bloomberg School of Public Health and The Berman Institute of Bioethics, Johns Hopkins University, USA. All photographs included in this document have been taken with consent for use in publications.

\section{GAIN DISCUSSION PAPER SERIES}

The GAIN Discussion Paper series is designed to spark discussion and debate and to inform action on topics of relevance to improving the consumption of nutritious, safe foods for all, especially the most vulnerable.

The Global Alliance for Improved Nutrition (GAIN)

Rue de Varembé 7

1201 Geneva

Switzerland

T: +41 227491850

E: info@gainhealth.org

www.gainhealth.org

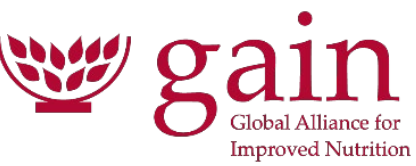




\section{SUMMARY}

This paper considers whether Public-Private Partnerships (PPPs) focused on improving diets and nutrition can simultaneously advance public health nutrition goals and business goals. Discussion around the efficiency of PPPs is polarised in the field of nutrition: they are seen to have considerable potential to improve diet and nutrition outcomes by harnessing resources, reach, relationships and knowledge, but there is also some mistrust of private-sector actors and their motives.

There has been little published on how PPPs operate in practice for diet and nutrition outcomes - i.e., how these partnerships are formulated and structured and how conflicts of interest are prevented, minimised, and managed. Accordingly, little is understood concerning the factors that shape PPPs' ability to improve diet and nutrition population outcomes.

This paper explores the following questions: What is it about food and diets that makes it especially challenging for the public sector to engage and work with the private sector and, in turn, formulate PPPs? Why is there a lack of evidence and documentation about what has and has not worked with PPPs in the food systems domain? How do we address impediments and incentivise the creation of more PPPs that have potential to advance diet and nutrition outcomes whilst remaining commercially sustainable? How do we negotiate the complex nutrition terrain to make progress? The paper offers a range of insights, solutions and guidelines on how to increase the likelihood of PPPs being impactful and accountable.

\section{KEY MESSAGES}

- Improving diets and nutrition requires engaging and working with the private sector, given its significant involvement and power across the food system.

- More evidence is needed on food system-specific PPPs to determine if and how they work to advance better diets and nutrition, including actual impact data and evidence of what constitutes 'success.'

- To address trust, more open discussion is needed, including laying out conflicts of interest and creating norms of respect for different opinions.

- Governments should create appropriate incentives for the private sector to positively engage on public health nutrition goals, along with disincentives for contributing to negative outcomes.

- To enable successful PPPs for better public health nutrition, stakeholders will need to think creatively, engage with diverse partners in and out of the food system, and adapt successful approaches from other sectors.

- While PPPs as not the sole solution for fixing the problems of malnutrition within the food system, they are a potential solution when implemented well. 


\section{BACKGROUND AND OBJECTIVE}

Every country, across all socio-development levels, is affected by malnutrition in some form, be it undernutrition, micronutrient deficiencies, or overweight and obesity, with some countries struggling with multiple forms (Swinburn et al. 2019; DI GNR 2019). These types of malnutrition present major impediments to achieving sustainable development, with crippling consequences for human health, the environment, and social cohesion (Swinburn et al. 2019; Willett et al. 2019).

One of the most impactful solutions to address this challenge is to improve the composition of dietary patterns through the interconnected food system. However, diets are changing along with dynamic development, urbanisation, and shifting demographics (Popkin et al 2012; Popkin et al 2020). Unhealthy diets are now one of the top risk factors globally for deaths and disability-adjusted life-years (DALYs) lost, surpassing, for example, tobacco smoking and high blood pressure (Afshin et al. 2019). Most of these diet-focused deaths and disabilities are in the form of non-communicable diseases including ischemic heart disease and diabetes mellitus (Afshin et al. 2017).

Obesity and undernutrition are both diet-focused problems (Scott 2017; DI, GNR 2019; Swinburn et al. 2019; FAO 2019). Many people today are more likely to have more access to highly processed, packaged foods that are depleted of nutritional value (but high in added sugars, salt, and saturated and trans fats) than to fruits, vegetables, nuts, legumes, and some animal-source foods, some of which are cost-prohibitive (Baker and Friel 2016; Lawrence and Baker 2019; Hall et al 2019). Consumption of these nutrient-poor food products is linked to the onset of obesity and perpetuates micronutrient deficiencies, which are also exacerbated by food insecurity and the lack of access to affordable, nutritious foods (FAO 2018).

The types of foods that people can easily consume have to be altered to ensure public health and nutrition gains. However, to realign food systems and to respond to dietary transitions, it is not sufficient to only 'fix' the problem at particular stages of the food supply chain or food environments. It is important to focus on which actors are pulling the levers and driving food system change and how they interact or work with other actors. It is also necessary to understand in what context these actors work, what shapes the emergence and effectiveness of their interactions with each other, and in what type of enabling environment (FAO 2018). Getting the incentives and accountability mechanisms for addressing all forms of malnutrition right is essential if the goal is to change actors' behaviour towards improving the affordability and accessibility of foods and beverages that support healthy diets (Mozaffarian et al. 2018).

To argue that there should be no engagement with the private sector is not realistic. A healthy diet is critical to achieving and sustaining adequate nutrition and ultimately nutritional status. Food and drink, the mainstay of the diet, is primarily provided by a "broad range of commercial enterprises" -even in low- and middle-income settings where small- and mediumsized enterprises (SMEs) are vitally important for the poor-and the food industry has the capacity for market penetration far beyond that of the public health sector (Fanzo and McLaren 2019). Thus, the private sector has an important role to play in ensuring food supply chains and environments are delivering healthy diets, given appropriate incentives are in place (Levine and Kuczynski 2009). Indeed, the private sector - including but not limited to food and beverage 
companies - has considerable potential to ensure food systems and environments are producing nutritious foods through reformulation and other mechanisms. Furthermore, the private sector has significant power across the food system, with involvement in almost all aspects of the production, processing, distribution, marketing, and sale of food and beverages that consumers eat and drink every day (Dukeshire 2013; Clapp and Isakson 2018; Clapp 2017).

Many of those working with and within food systems are calling for the private sector, in all its shapes, forms, and sizes, along with its supporting ecosystem, to become increasingly aligned with the nutrition and health needs of consumers, pioneering sustainable production and distribution methods, and protecting the environment. Some look to Public-Private Partnerships (PPPs) as an advantageous vehicle for realising public goals, in this case, public health nutrition, whilst stimulating private investment and additional resources to foster development in food systems (Hamann et al. 2011; Yach 2008a, 2008b; Yach et al. 2010; G. Sacks et al. 2013; Drewnowski et al. 2018). It is thought that PPPs are advantageous because they combine, ideally, the best of both worlds - goals oriented toward the public interest (public-sector angle) with national reach, sustainability, innovation, efficiency, and costeffectiveness (private-sector angle). However, multiple barriers exist that make such partnerships challenging (Kraak et al 2019).

This paper summarises the range of factors that affect the formation and development of PPPs in food systems that are meant to address healthy diets and public health nutrition goals. Factors that hinder their emergence and success in contributing to public health nutrition, as well as factors that facilitate their growth and effectiveness, are assessed. A wide range of PPPs were examined, including some that will have significant changes to public health and others that make smaller yet meaningful impacts. Several case studies outline lessons for future PPPs that span these scales. By understanding challenges and successes, we can move towards a greater number of more meaningful and impactful partnerships.

The purpose of this paper is to discern factors that would facilitate the impact of PPPs within food systems that more effectively achieve socially beneficial outcomes for healthy diets and nutrition. To do so, we highlight the factors that influence the functioning and success of PPPs for diets and nutrition, the current state of play of those factors, and what can be done to improve those factors. By understanding these hindrances across PPPs for diets and nutrition, we can move towards meaningful and impactful partnerships instead of repeating the mistakes of the past that have left too many in a crisis of confidence. This lack of confidence reduces the motivation to trust or engage across the public-private divide.

To address these critical issues of PPPs for diets and nutrition within food systems, we asked two overarching research questions:

1. What makes PPPs for diets and nutrition within food systems so challenging to establish and succeed?

2. How do we ameliorate impediments and incentivise the creation of more PPPs within food systems that stand a good chance of generating and sustaining improved diet and nutrition outcomes? 
This paper focuses only on PPPs that take place in food systems with an aim to improve diets and nutrition. Although there are many other types of PPPs that are geared towards improving nutrition, and many other types of PPPs within food systems that shape other outcomes (e.g., economic growth, environmental sustainability), taking a broader approach is beyond the remit of this paper. Furthermore, whilst we aimed to be comprehensive in our case studies, there are many examples out there that we may have missed, have not been documented, or have not been evaluated by a third party.

\section{METHODOLOGY}

An extensive literature review was performed, and key informant interviews were conducted to answer our research questions. Brief case studies highlight key themes and learnings that emerged from the literature, as shown in Appendix 1.

\section{Framing}

For the purposes of the paper, we have summarised our findings into factors that influence the functioning and success of PPPs for diets and nutrition, the current state of play of those factors, and what can be done to improve those factors. Factors emerged and were clustered into three prevailing areas from the literature search and interviews: motivation, means, and measure of success. These are defined as follows:

- Motivation is the reason and willingness to participate in PPPs for diets and nutrition. For the purposes of this paper, they are the factors that influence the formation of these PPPs.

- Means indicates the actions by which a result is brought about. In this case, the means are the factors that facilitate the trust and willingness to engage in PPPs for diets and nutrition. Means can be resources, methods, tools, and guidance to facilitate the trust and willingness to engage in these PPPs.

- Measures of success indicate the best practices to ensure PPPs for diets and nutrition function well and are results oriented. In this case, these factors impact the success of these PPPs.

\section{Literature review methods}

Information on nutrition-focused PPPs was collected by searching Google Scholar and PubMed since 2000. Eighteen search terms and their combinations were used including: "public-private partnerships AND nutrition," "PPPs AND diets," "PPPs AND food systems," "PPPs AND food sector," "PPPs AND nutrition," "private sector AND nutrition," "industry AND nutrition," "business AND nutrition," "impact assessment PPPs AND nutrition," "PPPs AND healthy food," "PPPs AND obesity," "PPPs AND undernutrition," "PPPs AND malnutrition," "marketbased approach AND nutrition," "collaborative governance AND nutrition," "PPPs AND nutrition AND health outcomes," "commercial sector AND nutrition," and "private-public partnership AND food safety." The literature review was restricted to articles in English that were broadly associated with PPPs or private-sector involvement in the nutrition field. The search resulted in 113 peer-reviewed and grey literature articles, which were then divided into the following categories: critiques, reviews, or analyses of nutrition-focused PPPs; private sector 
involvement in nutrition research; case studies of nutrition-focused PPPs and other PPPs with a focus on public health or agriculture.

\section{Key informant interviews}

Between August 2018 and February 2019, semi-structured interviews were undertaken by telecommunications with those who had written extensively on PPPs from a research perspective, those who were directly involved with PPPs or those who had extensive knowledge of private- or public-sector involvement in nutrition. Individuals were identified through the literature review and by asking interviewees whom they considered to be most centrally involved in nutrition-focused PPPs. Thirty interviews with respondents from high-, middle-, and low-income countries were conducted; the interviewees had various organisational affiliations and expertise in food systems and nutrition, as shown in Table 1. Using a purposive (selective) rather than sampling selection strategy, the aim was to reach theoretical saturation: the point at which all major themes have been identified and additional interviews are unlikely to reveal new information.

The interviews lasted approximately one hour and were recorded and transcribed with permission from the key informants. We obtained informed consent from all research participants. The study protocol was cleared through the Institutional Review Board of the Johns Hopkins University, which granted the study exempt status because it focused on public policy and was deemed to pose minimal risk to informants. All interview transcripts and notes were de-identified and secured in password-protected documents to ensure respondent confidentiality. Each interviewee was asked individualised, open-ended questions, depending on his or her background and involvement in PPP efforts within food systems with a goal to improve diets and nutrition outcomes.

Drawing on the findings from the literature review, questions were focused on successes and challenges of high-quality and impactful PPPs in food systems for diets and nutrition outcomes. Appendix 2 includes the interview questionnaire guide.

\section{Qualitative analysis methods}

Thematic analysis was performed in Microsoft Word on collected information from the key informant interviews and literature review to analyse factors shaping PPPs in food systems for nutrition outcomes, which are presented in the findings section of the paper. To minimise bias, data sources were triangulated, always corroborating information from interviews with written sources. To ensure anonymity in reporting the interview data, each key informant was assigned a number. Throughout the paper, the reader will see references to interviews labelled I with a number along with quotes taken from interviews to illustrate key points. 
Table 1. Interviewee affiliations

\begin{tabular}{|c|c|}
\hline Organisation Type & Affiliation \\
\hline \multirow{9}{*}{ Academic/Research } & City University \\
\hline & Cornell University \\
\hline & Institute of Medicine \\
\hline & International Food Policy Research Institute \\
\hline & New York University \\
\hline & Pennsylvania State University \\
\hline & SR Strategy \\
\hline & University of Guelph \\
\hline & Virginia Tech \\
\hline \multirow{8}{*}{ Private Sector } & BASF \\
\hline & Compass Group Canada \\
\hline & Emerging Ag Inc. \\
\hline & Partnering with Purpose \\
\hline & PepsiCo \\
\hline & Royal DSM \\
\hline & Unilever \\
\hline & World Business Council for Sustainable Development \\
\hline \multirow{7}{*}{$\begin{array}{l}\text { Public Sector (including non- } \\
\text { profits) }\end{array}$} & 1000 Days \\
\hline & $\begin{array}{l}\text { Bangladesh Rural Advancement Committee (now Building Resources } \\
\text { Across Communities) (BRAC) }\end{array}$ \\
\hline & International Development Research Centre (IDRC) \\
\hline & International Food Information Council (IFIC) Foundation \\
\hline & Nutrition International \\
\hline & PATH \\
\hline & Save the Children U.S. \\
\hline \multirow{4}{*}{$\begin{array}{l}\text { Combined Private and Public } \\
\text { sector alliance }\end{array}$} & MotherFood International \\
\hline & Sight and Life \\
\hline & Global Alliance for Improved Nutrition (GAIN) \\
\hline & Scaling Up Nutrition (SUN) Business Network \\
\hline \multirow{2}{*}{$\begin{array}{l}\text { Intergovernmental } \\
\text { organisations }\end{array}$} & UNICEF \\
\hline & World Health Organization \\
\hline
\end{tabular}

\section{DEFINING TERMS}

\section{PPPs}

Many PPPs are considered social alliances designed to achieve common goals benefiting societies and all partners (J. E. Austin 2000; Kraak and Story 2010; Kraak et al. 2012). Yet there is significant confusion in defining PPPs because they entail a mixture of interactions involving a range of different activities and a range of processes and structures for interaction (J. Hoddinott, Gillespie, and Yosef 2016). For example, there is an important distinction between 
interactions characterised by "shared decision-making power among partners" and those characterised simply by "participation" from both sectors (Hawkes and Buse 2011).

In the field of nutrition, there is no single definition of a PPP and there is no consensus yet on how they should be defined. In fact, the notion of PPPs in nutrition and health has not been broadly accepted (Yach 2008b; J. Hoddinott, Gillespie, and Yosef 2016; J. F. Hoddinott, Gillespie, and Yosef 2015; Bryce et al. 2008; Gillespie et al. 2013). Despite nuanced differences around defining PPPs in nutrition, the literature and many informants interviewed for this analysis articulated PPPs to be partnerships that involve at least two actors (Mendel and Brudney 2012; Kaan and Liese 2011; Kumaraswamy et al. 2007; J. Austin and McCaffrey 2002):

"Public-private partnership is a form of multi-stakeholder partnership...I don't think today two stakeholders can be part of the solution. I think you need more than two stakeholders" (I3).

"The way that PPPs have been used in the nutrition and food sector are much more general...I would take the capitals off the Ps, and it speaks more to how different sectors have collaborated, to deliver something in our interest. It makes more sense to speak in those terms" (I10).

PPPs have also been referred to as Public Private Engagements (PPEs). This is defined by the OECD as an activity that aims to engage the private sector for development results and involves the active participation of the private sector. The definition is deliberately broad in order to capture all modalities for engaging the private sector in development co-operation from informal collaborations to more formalised partnerships (OECD 2016). The concept of the private sector-led partnership can be referred to as a private-public engagement (PPE) where business convenes "multiple entities-families, schools, communities, policymakers, the media, and nongovernmental organizations, among others-to address health-related issues"

(Drewnowski et al., 2018).

For the purposes of this paper, the authors utilise the World Health Organization (WHO) (2011) definition of PPPs:

"A collaboration between public-and private-sector actors within diverse arrangements that vary according to participants, legal status, governance, management, policy setting, contributions and operational roles to achieve specific outcomes."

Specifically, this paper focuses on PPPs formed to address key issues and actions within food systems that are meant to focus on improving diets and nutrition.

\section{The three "Ps"}

Another area requiring nuance is defining what the individual terms "public," "private," and "partnership" mean. In some instances, PPPs may be a legally defined term (that is, a legally binding contract or procurement). In other jurisdictions, PPP describes a different way of delivering services, which may be implemented under one or more different types of contracts (Hoddinott et al 2016). What is clear is that both public and private sectors are vast and have many different types and scales of actors who act in different ways. 
The public party can encompass governments (the respective procuring authority), research organisations, companies, or entities that may act in the respective contract as procuring authorities in the name of the government. These parties include private for-profit companies and individuals, private not-for-profit organisations that are often but not always community or religious based and donor organisations (including multinational donors, bilateral donors, and private donors). Partners also include governments at the national and local level, public organisations, and community groups that may be either public or private, depending on their purpose and structure (IOM 2012).

\section{Private}

The private party includes the company or companies that will act as a "private partner" in the partnership. The "private sector" in food systems literature is often referred to with the homogenising term "industry," which tends to conjure the idea of multi- and trans-national food and beverage companies or corporations. However, the private sector is made up of many different types of companies with a wide range of sizes, scales, and human and financial resources, as well as varying reach into local, domestic, and international markets.

The Global Panel on Agriculture and Food Systems for Nutrition defines the private sector in the food industry as encompassing agribusiness; food and beverage manufacturers; food retailers including supermarkets, food service providers, industry trade associations, food wholesalers, food distributors, importers and exporters; and the advertising and marketing industry. It characterises all parties as playing significant roles in food transformation including product processing, reformulation, and packaging - with varied businesses such as dairies, abattoirs, meat-cutting plants, mills, fruit and vegetable preparation and packing centres, and meal manufacturers (Glopan 2018), as shown in Figure 1 (HLPE 2017). There are also many actors that are not necessarily directly involved in the food system and its activities, but their products and services influence food system change, such as the mobile phone industry, financial services companies, advertising and communications agencies, and refrigeration and haulage industries.

Amongst interview respondents, there was consensus for a need to better define PPPs and lay out who and how actors are defined in both the public and private spheres, particularly with respect to there being a range of actors in both $(12,16,18,19,115,119)$ :

"There needs to be a much better understanding about who we are actually talking about in terms of the public sector. And in terms of the private sector, what type of private sector with the understanding that...it's a monolithic term and there is a wide spectrum of different actors that...fall within this umbrella of a private-sector actor, everyone from... at the local level, a small fruit-andvegetable operator, for example, to a large multinational conglomerate that makes food and beverage products" (I15).

For the purposes of this paper, the authors take a broad stance on what constitutes the private sector, but most of the literature and those interviewed focus on the larger-size entities of the private sector as well as the multi-national companies. 
Refrigeration, preservatives, testing equipment
Farms, ranches, fisheries, agricultural

input companies (seeds, etc)

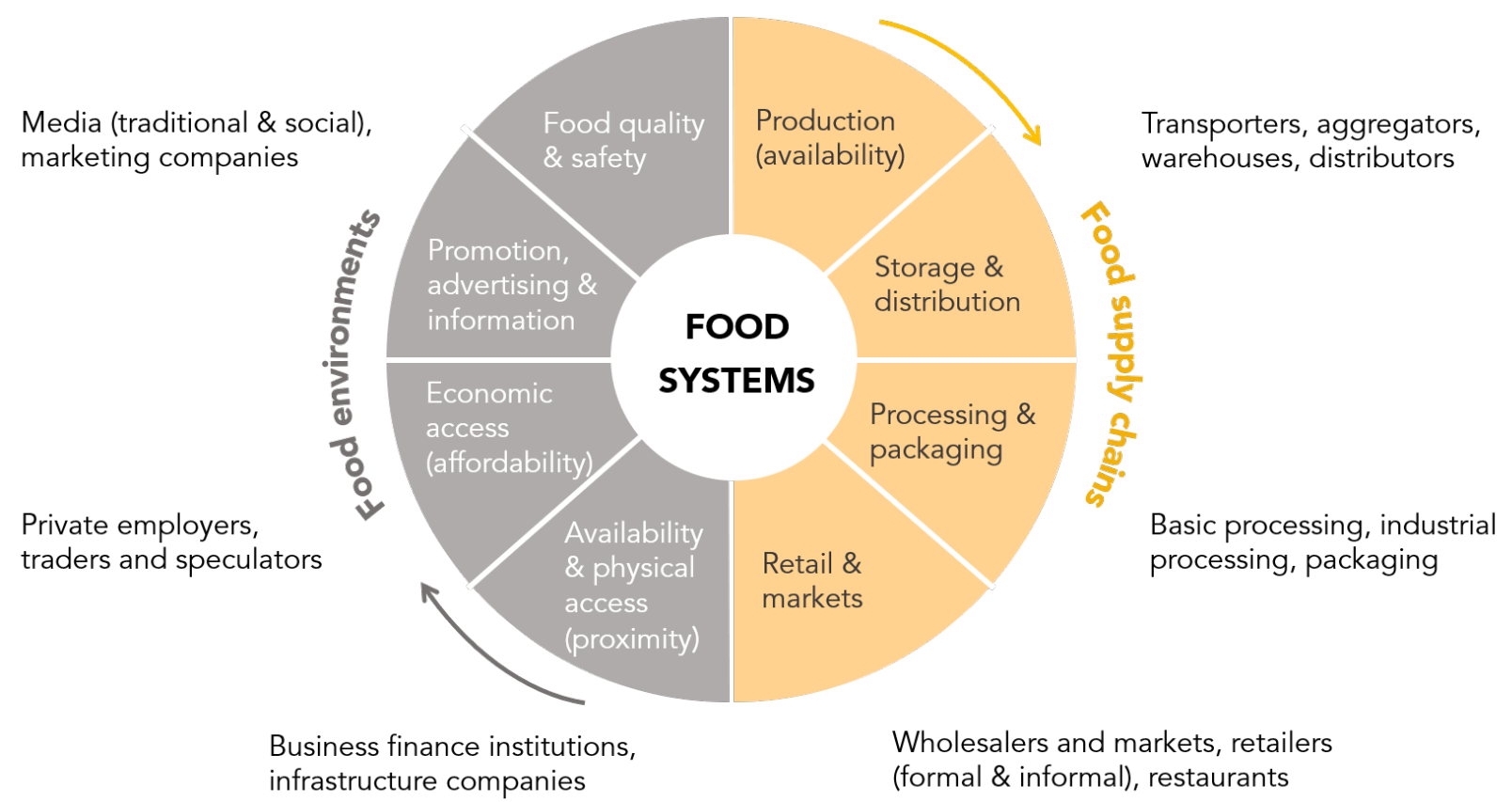

Source: Adapted from HLPE (2017) and L. Haddad and S. Morris, GAIN

Figure 1: Food and non-food private sector engagement across food systems

\section{Partnership}

Based on the literature, the concept of "partnership" encompasses a mélange of interactions involving a range of activities, from education campaigns to joint research activities, and multiple processes and structures for interaction (Hoddinott et al 2015). Partnerships have been described as "a relationship based upon agreement, reflecting mutual responsibilities in furtherance of shared interests" in which there is a foundation of shared goals that are underpinned by an agreement on key principles (Buse and Walt 2002). Partnerships have been further described as not only an agreement between two or more partners with a common interest in some outcome of the partnership but also a common understanding of what is expected from each partner and a belief that each partner will perform in accordance with the agreement that has been established (Mitchell 2008).

In the health sector, WHO describes partnership as a means to "bring together a set of actors for the common goal of improving the health of populations based on mutually agreed roles and principles" (Kickbusch and Quick 1998). In this definition, agreement on key principles is thought to be crucial, as is the maintenance of a balance of power between the parties to enable each to retain its core values and identities (Buse and Walt 2000).

Some definitions incorporate an operational element by envisioning a partnership as "a collaborative relationship between entities to work toward shared objectives through a mutually agreed division of labour," as defined by the World Bank (Wolfensohn 1998). This type of partnership may also include "a mechanism to assess success and make adjustments" or "an agreement to work together to fulfil an obligation or undertake a specific task by committing resources and sharing the risks as well as the benefits" (Buse and Walt 2000; Webster and Sansom 1999). 
Interview respondents described partnership in different ways $(13,14,15)$. One respondent noted the underlying motivation for a partnership's development:

"The rationale for the partnership is that they're addressing an unmet need.

They're focusing on under-resourced priorities. 'We're going to do this together because neither one of us can do this on our own,' and they are all working toward creating a synergy that adds value to whatever they plan to do" (I5).

\section{WHY PARTNER?}

There are a range of partnerships depending on the end goal, particularly for food systems (Rowe et al. 2013). They can be research driven or commercially focused and designed to promote public events, to promote or administer public health initiatives, or to essentially be sponsorships, in which one public partner performs a public service of some kind and the private-sector partner provides financial and/or other resources, including but not limited to expertise, training, and access.

What is clear is that some partnerships involve a minimal level of commitment from each partner. At one end of the spectrum, this could be an agreement to provide straightforward transactional service delivery or a contract to provide a piece of equipment to a public facility. At the other extreme is a partnership in which two or more organisations agree to pool resources in a particular area, share all decision making, and market and provide services jointly. Between these two extremes lie a wide range of levels of commitment between partners.

It is important to consider whether a partnership is indeed necessary for tackling a specific public health nutrition objective. The WHO developed a tool to help partners decide whether or not to engage (114). They argue that PPPs should align and comply with WHO's mission, priorities, policies, and procedures. This overarching criteria for engagement should be considered to ensure goal alignment is clear. Hawkes (2011) suggests that before engaging with private sector, three questions should be answered:

1. Would engaging with private sector help achieve the objective faster and more effectively?

2. Would the interests involved (on both sides) enhance or threaten the likelihood of achieving the specific objective as well as longer-term public health objectives?

3. If interaction is a viable option, what form of engagement would most effectively achieve the objective whilst accounting for the different interests: a real partnership or a less formal type of collaboration?

\section{FINDINGS}

Stemming from the literature, interviews, and case studies, a series of factors emerge that influence the functioning and success of food system-specific PPPs for diets and nutrition. The findings are divided into motivating factors, the means or actions to facilitate these PPPs, and measures of success. In some instances, there are overlaps in recommendations of what is needed to support the three types of factors, which further underscores their importance. Table 2 summarises 10 motivation, mean, and measure factors for PPPs. 


\section{THE MOTIVATIONS}

Once individual parties have identified their own incentives to work with others, there need to be appropriate underlying elements that support the set-up of a partnership. In this section, we highlight four ideal motivating factors that would influence the formation of PPPs. The factors, the current state of play, and what could be improved to address these factors are elaborated on below.

\section{FACTOR 1: STAYING SOLO AND SILOED}

\section{State of Play}

There is some, though not universal, recognition that public- and private-sector efforts are insufficient working on their own to advance public health nutrition goals. Many of the current dietary and nutrition-related challenges would be well served by PPPs, with all stakeholders engaged. Moreover, the complexity of some of today's challenges, such as obesity and poor diets, demand collaboration. One of the greatest benefits of working together to tackle complex these challenges is the greater variety of expertise, perspectives, and resources brought to the table when multiple sectors convene.

Both the private and public sectors play vital roles in modifying the food supply for public health purposes because the majority of food consumed is made by the private sector-from large, multi-nationals to local SMEs. Without active involvement of the private sector, "how can we hope to modify the food supply?" (NAS 2012). The public sector needs to be involved because of its knowledge of public health and its insights into issues of which the private sector may be unaware.

There is an appreciation of the scope of possibilities that different private-sector players can offer to advance public health, especially within the food system. However, there is a variable range of acceptance. Some of this is due to many in public health equating the private sector with "big food." However, many other opportunities are being missed if the private sector is viewed as only trans- and multi-national companies that hold significant power within food systems. It is clear that a range of food and non-food companies, from small to large, are involved in food systems, and not all should be grouped in as one entity.

However, not everyone agrees. Some argue that engaging with the private sector is a "no go" because of the inherent conflicts of interest between corporations that profit from unhealthy food and public health collaborations. Some public sector and academic nutrition actors take a stand to not have any engagement with industry, no matter how beneficial the partnership could be for public health and even if behaviours of a certain company have had positive health outcomes. Others take the opposite stance and find it unrealistic to not engage with the private sector because they are such significant actors in the food space-these actors are often shunned by the first group. Others yet stand somewhere in the middle, open to engagement but not to official partnership, communicating but not entering into financial or advisory agreements.

"Because growth in profit is the primary goal of corporations, self-regulation and working from within are doomed to fail" (Stuckler and Nestle 2009). The reasons are two. The first is that there is no evidence for an alignment of public health interest in curbing malnutrition with that 
of the food and beverage industry. The second reason is the "precautionary principle." Because it is unclear whether inherent conflicts of interest can be reconciled, it is better to proceed on the basis of evidence. The authors argue that taking these views puts pressure on the private sector to act in good faith towards public health.

\section{How to Improve}

The United Nations System Standing Committee on Nutrition's (UNSCN's) list of potential risks of private-sector engagement as described in the committee's private-sector engagement policy (UNSCN, 2006). These include the following:

- $\quad$ "Greater corporate influence over public policy";

- $\quad$ "The opportunity costs of distraction from or less interest in activities which are not of interest to the private sector but may be important for nutrition goals";

- $\quad$ "Regarding private sector engagements as ends in themselves, thereby undermining strategic direction";

- $\quad$ "Loss of legitimacy with key constituencies and funders due to perceived cooptation by commercial interests"; and

- $\quad$ "Funding driven shifts in priorities at both international and national level, with fragmentation of public health/nutrition policies."

The UNSCN places an emphasis, "above all," on the need for "being open and clear about potential conflicts of interest" (UNSCN, 2006).

Following a multi-stakeholder technical consultation in 2015 and a public consultation in 2017, the WHO published a draft approach to prevent and manage conflicts of interest in both the policy development and implementation of programmes at the country level (WHO, 2017). In its typology and general principles, the WHO stresses that a conflict of interest implies a risk of improper action occurring rather than the conflict being a certainty. The approach proposes a methodology for countries to consider when engaging with individuals and non-state actors (including nongovernmental organisations, private-sector entities, philanthropic foundations, and academic institutions). It offers a valuable decision-making tool for country governments to use when considering whether or not to engage with these entities, as shown in Figure 2, and is directly applicable in the case of PPPs. Box 1 shows some examples of unique PPPs where multiple partners come together to make change. 


\section{BOX 1. WORKING TOGETHER}

- mNutrition, a behaviour change communication programme, offers an example of public agencies working with companies beyond the food industry to impact public health nutrition in eight countries in Africa. This is a partnership between the UK Department for International Development, the Norwegian Agency for Development Cooperation, and GSMA (a global mobile phone network alliance) and implemented by local mobile phone network providers (e.g., Vodafone, MTN, Safari, Airtel) with content providers such as CABI, WHO, and IFPRI (the combination of partners varies by country). The project develops and disperses health and agriculture mobile phone messaging and carries out real-time nutrition data monitoring. Furthermore, a multi-agency third-party evaluation team was contracted to estimate the impact of this programme in two of the countries where it is carried out.

- The Partnership for Maternal, Newborn, and Child Health (PMNCH) offers a framework that extends beyond government and the private sector to also include research institutes, a private foundation, professional networks, and civil society organisations, hosted by a multilateral organisation (WHO). While this is a network rather than a contractual partnership, its multistakeholder governance structure, which supports its mission to increase the engagement, alignment, and accountability of partners provides a basis upon which focused nutrition partnerships may draw ideas. 


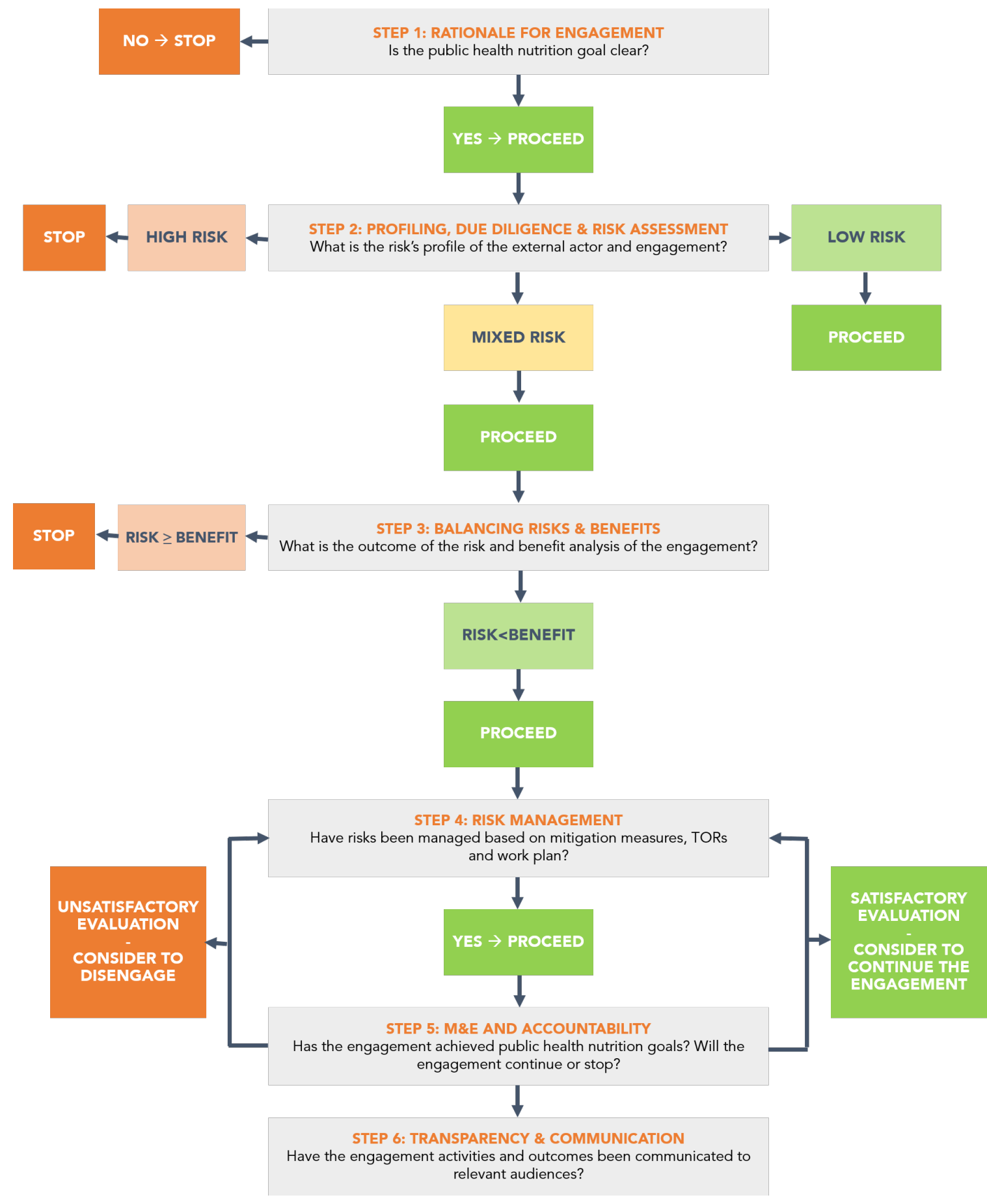

Figure 2: Decision-making tool for non-state actor engagement for public health and nutrition Source: WHO (2017); Ralston et al (2020); permission for reproduction granted. 


\section{FACTOR 2: INSUFFICIENT EVIDENCE AND TOOLS}

\section{State of Play}

Currently, there is not a strong body of evidence that food system-specific PPPs work for diets and nutrition. There is insufficient evidence on actual impact, data, or concluding evidence of what constitutes "success" (Save the Children, 2017). Most PPPs are still in early or pilot phases that do not allow for proper evaluation, and many exist as pilots with less certainty for scale-up to serve consumers that need interventions or provisions the most (Save the Children 2017).

Monitoring and evaluation go hand in hand with enforcement and transparency $(11,15,16,112)$. There has been a historical failure, or at least minimal evaluation of what has made PPPs effective and what has hindered progress (van Liere et al. 2017).

As one interviewee noted, "The other risk is that the resources required for a great evaluation or series of evaluations or the resources required for proper monitoring and interpretation and enforcement, could be a stumbling block, likely would be because as we're saying, the complexity of the problem is such that it would take enormous resources to untangle what's actually going on and where the accountability or blame lies if the articulated goals are not being achieved" (I12).

\section{How to Improve}

There needs to be a substantial effort to generate more evidence in which public-sector partners insist on evidence and private-sector partners accept the notion that third-party evidence gathering is necessary. There is also a need to support the development and aggregation of new tools, approaches and data to design and evaluate the specificities of PPPs.

However, there are also valuable lessons to be drawn from high-quality PPPs in other sectors, such as infrastructure, agriculture, and health (Ruckert and Labonté 2014; Ferroni and Castle 2011; Ponnusamy and Others 2013; Spielman, Hartwich, and Grebmer 2010; Lawther and Martin 2015). Lessons from other sectors show that effective, high-quality partnerships consist of trusting relationships that share information; leveraging of financial or in-kind resources, expertise, influence, networks, and distribution systems; and management of legitimacy and the collaborative structure to ensure that organisational assets are aligned with common missions, goals, and objectives to reach populations with larger-scale activities than each partner can deliver on its own (Kraak et al. 2012). Box 2 provides some real-world examples of impact of PPPs.

In other sectors, PPPs made a concerted effort to balance private commercial interests with public interests (Zhang Xueqing 2005). This was largely due to proper due diligence taken to ensure compliance with ethical codes of conduct (Marks 2014) and monitoring and evaluation of partnership outcomes (Hodge, Greve, and Boardman 2010).

Because food is so critical for nutrition, PPPs present a challenge as compared to other sectors. Successes in infrastructure or water, sanitation, and hygiene (WASH) PPPs are less contentious because a road or soap is largely a "neutral" commodity, whereas food is not (Curtis et al. 2011). Food holds a special place in society and is considered an exceptionality (Thompson 2017). Food touches on multiple aspects of culture and is embedded in all societal aspects of life. It is often considered a right, and therefore an issue of justice and sovereignty. This makes PPPs that involve food products particularly more contentious within society. Whilst it is important to take into 
consideration the 'personal' nature of food, this should not be an obstacle to learn from other challenging partnership spaces like health and agriculture.

\section{FACTOR 3: POOR TRACK RECORDS}

\section{State of Play}

There has been historic mistrust and hesitation to engage between the food industry, nutrition experts and non-governmental organisations, which has in turn hampered collaboration and the development of constructive, available solutions to malnutrition and diets, particularly in food systems (Eggersdorfer and Bird 2016). Where did this mistrust come from and why? What is it about the food systems and nutrition that is especially challenging when it comes time to engaging and working across the sectors and, in turn, formulating PPPs? 


\section{BOX 2. BRINGING EVIDENCE TO THE TABLE}

One example of an impactful PPP is Gavi, the Vaccine Alliance. Through partnership between multiple public and private entities, including pharmaceutical companies, Gavi aims to increase access to immunisations across the developing world. In addition to a conflict of interest policy, it supports private-sector representation while mitigating potential power imbalances by limiting two of its 28 board positions to industry associations. (See Appendix 1 for this case study).

The non-profit organisation PATH provides an early and longstanding example of how engagement between the private and public sectors can achieve positive outcomes in the health sector. As a pioneer of the PPP sub-category Product Development Partnership (PDP), it has aggregated funding for vaccine development where commercial incentives are lacking. PDPs enable concurrent public and private engagement, which speeds up product development and licensing, as well as promoting the sharing of risk, resources, and knowledge. However, criticisms of this model suggest its focus on product development and delivery as being detrimental to national government investment in the health system. Furthermore, the stability of this model for PATH depends heavily on continued financial support from donor funding. Finally, and resonating closely with similar concerns in food system PPPs, is the conflict between public and corporate interests in increasing the uptake of vaccines. Businesses involved in such partnerships are provided with de-risked investment opportunities in new markets and intellectual property ownership whilst also boosting their reputation and positive publicity (Stevenson 2017).

Some of the mistrust from researchers and civil society and public sector actors is due to perceived deceptive behaviours of the private sector or profit motivations that trump public health motivations. Some of the literature cites valid challenges in the realisation of successful PPPs, largely due to conflicts of interest, power imbalances, and consumer and public-sector mistrust. Several rationales for this suspicion include: the lack of examples to learn from, insufficient dialogue amongst stakeholders about the 'how' and 'why' of PPPs, shortage of external, objective evaluations to demonstrate impact on nutrition outcomes, past transgressions by some private-sector actors, a particular worldview or ideology, and poor governance structures or political economy to enforce or incentivise PPPs agreements.

The private sector also has a trust deficit with public-sector, actors which shapes the former's interest in partnership (Eggersdorfer and Bird 2016). One respondent noted the hesitancy of companies producing unhealthy foods and beverages in partnering with the public sector given accusations and assumptions made by the public sector: "I don't think a multi-national beverage company is willing to work with a public sector that basically accuses them of making people obese. I think in the culture in these companies, there is certainly hesitation to work with the public sector" (I18). 
The issue of trust between some actors in the nutrition community and the private sector plays out in multiple ways when addressing malnutrition (De Costa, Johansson, and Diwan 2008). Larger, more established private-sector actors, particularly those that have undergone consolidation and have significant shares of key markets, have been known to use their power to override government voice and agency to set agendas (Scrinis 2016). Power asymmetries between public and private sectors were mentioned by several interviewees $(110,114,115)$, and the literature is beginning to examine this issue (Fuchs, Kalfagianni, and Arentsen 2009; Sodano 2006; Stevenson 2015; Pelto and Backstrand 2003; Chen 2018):

"Big Food corporations have used nutritional positioning to bolster their power and influence in the sector. Through lobbying and participation in nutritionally focused public-private partnerships, they have directly sought to influence policy and governance. Through market dominance in the nutritionally enhanced food sector, and participation in nutrition-focused rule-setting activities in agri-food supply chains, they have gained power to influence policy agendas. And they have used public outreach and the media to present their views on the nutritional aspects of their products, which shapes public perceptions and the broader regulatory environment. Together, these strategies have enhanced the power of Big Food firms to influence policies in the food sector" (Clapp and Scrinis 2017).

Governments face intrinsic tensions in their efforts to implement innovative policies to incentivise the production and consumption of healthy foods (Thow and McGrady 2014). At the same time, food and beverage companies see marketing and advertising, product placement, pricing policies, and packaging as a response to consumer demand. This view puts the responsibility solely on the consumer to make the "right" choice (Baker and Friel 2014; Malik, Willett, and Hu 2013; Monteiro et al. 2013; Monteiro and Cannon 2012).

Because the private sector has significant power across various aspects of the food system, it becomes difficult to envision a balanced partnership with the public sector if the latter's capacity to manage this relationship is sub-par. This unequal power relationship within PPPs can create an environment in which weaker partners (including local public and even smaller or medium-scale private-sector actors, civil society organisations, and community organisations) feel detached from the decision-making and management processes of partnerships (STC 2017). This detachment can lead to reduced ownership and agency of these actors, which can threaten dialogue on accountability and transparency. Some governments find regulating the nutrition and food space challenging due to a lack of capacity to govern, or the "will to govern" the multiple actors involved, amongst which the private sector tends to dominate (Mozaffarian et al. 2018).

\section{How to Improve}

To enhance trust amongst actors, strengthen the incentive structures and balance power, there may be a need to expand thinking beyond conventional alliances of PPPs. Not all PPPs mean that the private-sector partner is the food and beverage industry and the public sector is solely the government: many involved in food systems do not directly produce or handle food but have important roles in impacting the food system. There is a wider range of partners that bring different expertise to the table to work towards a common goal. More diverse alliances or consortiums that have multiple players - including not only government and the private sector but also civil society organisations that can be the watchdogs and researchers that can monitor progress and advise on the indicators of appropriate impact. That way, a partnership could 
potentially overcome issues that are inherent to the food systems community: (1) mistrust, (2) power imbalances, and (3) insufficient accountability and incentive mechanisms. This engagement creates a new ecosystem of partnerships that can be more inclusive, more balanced, and potentially more impactful.

It is important to focus on the sweet spot where partnerships can thrive-where the nature of the nutrition issue is clear, where the actors are not fragmented, and where the internal structures and goals are aligned (Figure 3). It is also critical to target the private-sector entities that have a positive track record; alliances with egregious violators of public health and nutrition norms should not be cultivated. Partnerships should be made up of those in the nutrition community who have pragmatism for what works to advance nutrition outcomes and are more open to partnering with the private sector. Those who are very opposed to the private sector should not be pushed to do so.

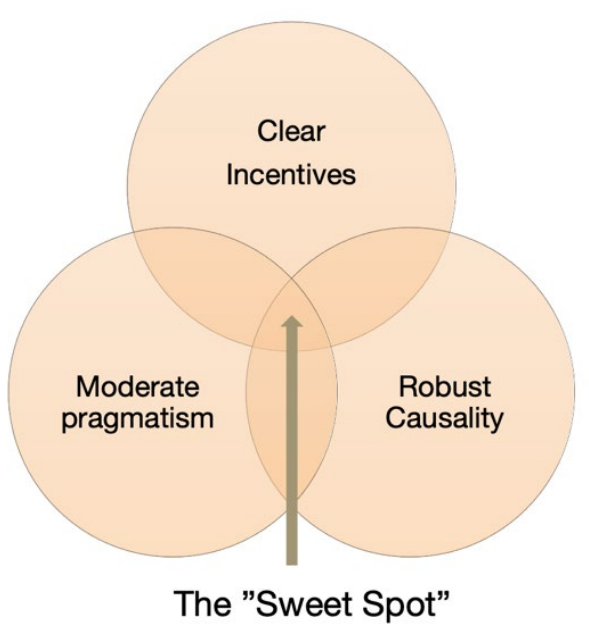

Figure 3. The sweet spot for PPPs

\section{FACTOR 4: VAGUE CAUSAL PATHWAYS}

\section{State of Play}

There remain challenges in identifying clear causal pathways in food systems to improve diets and nutrition. Some evidence is emerging, but there are still gaps in knowledge and evidence. Nutrition and dietary outcomes are a multi-temporal, multi-faceted, multi-sectoral, and multidisciplinary issue (Jerling et al. 2016). Because of this, there is no "silver bullet" to address malnutrition in all its forms. Much of the literature, derived from deep programmatic experience, shows that to address malnutrition in all its forms, multiple approaches, sectors, actors, and interventions are necessary (J. Fanzo et al., n.d.; Webb, Luo, and Gentilini 2015; del Carmen Casanovas et al. 2013; Smith and Haddad 2015; Garrett and Natalicchio 2010). Still, there is very scant evidence of how multisectoral approaches, particularly in food systems, can be effective for malnutrition in all its forms (Garrett and Natalicchio 2010).

Unlike malaria, malnutrition does not have a bed net or potential vaccine to prevent, a rapid diagnostic to test for the disease, or a pill to cure it. Nutrition involves food and the food system, which in and of itself is an "interconnected system of everything and everybody that influences, and is influenced by, the activities involved in bringing food from farm to fork and beyond" (Parsons et al 2019). To deliver healthy food requires agriculture, markets, and value chains, which involve a range of actors. It also requires healthy environments, functioning accessible health systems, empowered women, consumer awareness, and knowledge and care practices of mothers and fathers for their children (Aldermann et al 2013). To address nutrition through the food system poses numerous challenges, and because the path is not linear, the governing of that path is uncertain (Gillespie et al. 2013; Levine and Kuczynski 2009; Reich and Balarajan 2012; Balarajan and Reich 2016; Darnton-Hill and Samman 2015; Gillespie et al. 2013; Levine and Kuczynski 2009; Reich and Balarajan 2012; Balarajan and Reich 2016). Box 3 provides an example of a PPP focused on interventions with a more linear path to evaluate impact. 


\section{BOX 3. GETTING TO CAUSALITY}

Given the challenges of isolating the causal pathways of malnutrition, it is understandable that parties investing it solutions would favour interventions that can be easily administered and monitored and are more likely to demonstrate success. As part of the DSM-World Food Programme (WFP) partnership Improving Nutrition, Improving Lives, micronutrient powder sachets were distributed in refugee camps and emergency contexts in Bangladesh, Kenya, and Nepal. Impact (and its absence) of this intervention on anaemia, stunting, and diarrhoea among participating children, as well as on thinness and anaemia among lactating mothers, could be evaluated (Raj 2012; SBN n.d.). This ability to attribute outcomes to specific interventions is not ubiquitous in nutrition but provides a fertile space where collaboration can flourish. See Appendix 1 for a more detailed case study on this partnership.

Given the multi-faceted nature of malnutrition, there is a need for multiple interventions to be undertaken (Aldermann et al 2013). Thus, delivering nutrition is not straightforward, and many individual interventions have still not been subjected to careful evaluation to assess their impact, particularly where more than one intervention is in place. In this context, policymakers and implementers can be left in a void, without guidance to determine what constitutes sound evidence to justify an intervention, with whom to partner, and how (Garrett and Natalicchio 2010). Furthermore, without the ability to clearly measure impact, it is difficult to incentivise actors to come together to work on changing nutrition outcomes, particularly in the formation of PPPs. One respondent noted this: "Structurally, our field is very multidimensional and complex. This is in contrast to PPPs in public works. The outcomes and what needs to be done is very clear in infrastructure PPPs, but indicators in nutrition [are] not very clear" (19).

A lack of clear causal pathways makes it hard to know what to focus on, the role of each player involved, and the implementation of critical nutrition interventions (Hurlimann et al. 2017). Two interviewees $(19,112)$ expressed similar concern that a lack of nuanced understanding of the causal pathways, the complexity of these pathways and the potential to do harm without a clear understanding of them, heighten reservations to act and partner. One respondent likened the difficulties of measurement in nutrition to climate change:

"In the case of climate change, you can see the aggregate impact of automobile emissions or coal plant emissions, that can be estimated, and the goal becomes reducing those emissions. But the ability to demonstrate the impact of that on the temperature of the oceans and halting the receding of glaciers is far down the road, right? So, there's an analogy there in nutrition of can we agree on some approximate endpoints or is the only relevant nutrition goal going to be the more ultimate endpoints, biological endpoints that we tend to care about?" (I12). 


\section{MOTIVATIONS - Motivations that influence the formation of PPPs: Why partner?}

What factors influence the formation of PPPs?

1. There is recognition that public and private sector efforts on their own are insufficient to advance public health nutrition goals.

What is the current state of play?

There is notional buy-in to this idea, but in reality, highly variable acceptance.

2. The evidence that PPPs can work for public health nutrition, and the tools to guide and evaluate PPPs are in place.

3. The parties involved have a track record for being a credible partner and advancing positive public health nutrition outcomes.

4. There are solutions (public or private or both) to specific public health nutrition problems and the causal pathway is clear.

\section{MEANS - Means that facilitate trust and willingness of malnutrition and diets.}

Weak evidence and insufficient tools.

Pervasive mistrust and power imbalances exist.

Challenges in identifying clear causal pathways given the multifaceted nature
What is needed to improve?

Diversify partnerships to include food and non-food actors, as well as a variety of stakeholder types such as civil society and research that can hold to account.

Generate more and better-quality evidence. Public sector partners need to insist on this and private sector partners need to support this. Lessons from other sectors exist.

Identify the "sweet spot" where partners with a willingness and strong track record of positive public health nutrition efforts and outcomes converge. Success can breed trust.

Develop a stronger evidence base in the food systems space that demonstrates impact on public health nutrition. Continue to support PPPs that target specific problems with targeted and measurable solutions.

What factors facilitate the trust and willingness to engage in PPPs?

5. Public health nutrition professionals and business professionals are able to step outside their comfort zone and work through trust deficits.

6. Governments create the enabling environment with favourable incentive structures as well as disincentives for all parties involved.

7. Third-party brokers are able to connect the dots and foster transparent dialogue.

8. Involved parties have financial and technical resources for sustaining PPPs, promoting public health, and lessening risks for engagement.

$$
\text { is expected to bring in the finances. }
$$

What is the current state of play?

Difficult. Many public health nutrition professionals fear vilification or believe deeply that such cooperation is pointless and potentially unethical.

Weak and not favourable.

Too few - too uncomfortable for many.

Often unbalanced where private sector
What is needed to improve?

Facilitate more open discussion of the issues contained in this paper through meetings, blogs and viewpoints to build trust and establish a safe space for acceptable collaboration. Raise norms around the civility of discourse.

Create more incentives and disincentives for companies to produce more healthy foods through government commitment and action. De-risk through public-private investments.

Encourage the emergence and involvement of third-party brokers to facilitate PPPs.

Articulate the value of technical, human, network and other non-financial resources brought by public sector in order to address the resource-power balance which is otherwise often in favour of the partner with the most money on the table.
What factors impact the success of PPPs?

9. All parties are clear on the intended goals, processes and outcomes, and are vested.

10. Robust (rigorous methods, transparent assumption, full and publicly available reporting) accountability mechanisms are in place.
What is the current state of play?

Goals are often not aligned or not clear.

Accountability frameworks exist but no evidence that they are used.

\section{What is needed to improve?}

Ensure a partnership is the most effective way to achieve a specific public health nutrition objective. Support goal alignment in which all parties are clear on individual and shared organisational objectives.

Support more robust evidence on existing accountability frameworks and how they can be better utilised or adapted for PPPs. 


\section{How to Improve}

There is a need for a stronger evidence base in the food systems space that demonstrates impact on public health and nutrition with simple and specific actions that can be taken within a "sphere of certainty" in this complex problem. Whilst evidence is still accumulating, PPPs can focus on issues with robust causality-that is, where the knowledge base is greater and the evidence of causality and intervention impacts are solid.

Addressing micronutrient deficiencies is an area of nutrition that is more tractable and has therefore seen clearer evidence of impact in isolated interventions. As a result, the available literature on this type of intervention suggests PPPs lend themselves to micronutrient fortification and supplementation initiatives, although independent evaluations of their success are few (Hoddinott et al 2015). PPPs concerning supplementation and fortification are both more common and more likely to succeed, given that the issue and its impact are clear in delivering a public health good. Box 4 presents a case study of trans fat-where robust science informed policy, which implored the private sector to take action on reformulation.

\section{THE MEANS}

In this section, we highlight four factors that facilitate trust and willingness to engage in PPPs. These factors, the current state of play, and what could be improved to support these factors are outlined in Table 2, above, and expanded upon below.

\section{FACTOR 5: STEPPING OUT OF THE COMFORT ZONE}

\section{State of Play}




\section{BOX 4. REFORMULATION OF THE FOOD SUPPLY AWAY FROM TRANS-FATS}

Reformulation is a change to a food or beverage's processing or composition, often to either reduce harmful ingredients or nutrients—such as salt, added sugar, saturated and trans fats, and energy density-or increase beneficial ingredients or nutrients-such as fibre and protein. There are several examples of PPPs that have successfully removed trans-fat from foods. This is critical as the evidence of the negative health impacts of trans fat on cardiovascular disease is strong (Mozaffarian et al. 2006) as well as on the positive health impacts of reformulation (Mozaffarian et al. 2010).

In 2007, the Australia New Zealand Collaboration on trans fats was established as a PPP between representatives from the National Heart Foundation of Australia, the National Heart Foundation of New Zealand, the Dietitians Association of Australia, the Australian Food and Grocery Council, the New Zealand Food and Grocery Council, the New Zealand Food Safety Authority, and the government agency Food Standards Australia and New Zealand. This collaboration promoted initiatives to reduce trans fats in the food supply and to increase consumer awareness. Food manufacturers can voluntarily disclose the trans-fat content of their products, unless they make a nutrition claim about a product, in which case the disclosure is mandatory (Kraak 2012). Most food companies had voluntarily reduced trans fats in foods to what were regarded as acceptable levels in Australia's food supply (Food Standards Australia and New Zealand 2009a; b). This resulted in a decrease in trans-fat consumption by Australians below the WHO recommendation of less than $1 \%$ of total dietary energy per day (Kraak 2012).

The Public Health Responsibility Deal (RD) is a public-private partnership in England involving voluntary pledges between government, business, and other public organisations to improve public health. One such voluntary pledge refers to the reduction of trans fats in the food supply in England by either pledging not to use artificial trans fats or pledging artificial trans-fat removal. Knai and colleagues evaluated the RD and found that the RD contribution to trans-fat pledges in reducing trans-fat in England's food supply was negligible when looking beyond 2011. They concluded that voluntary reformulation via the RD has had limited added value, because the first part of the trans-fat pledge simply requires organisations to confirm that they do not use trans fats and the second part, that has the potential to reduce use, has failed to attract the participation of food producers, particularly those producing fast foods and takeaways, where most remaining use of artificial trans fats is located (Knai et al 2017).

This same research group assessed the impact across other domains beyond trans-fat elimination across six other pledges of the RD, including nutrition labelling (including out-of-home calorie labelling and front-of-pack nutrition labelling), salt reduction, calorie reduction, fruit and vegetable consumption, and reduction of saturated fats. We then analysed data on organisations' plans and progress towards achieving the pledges and assessed the extent to which activities among organisations could be brought about by the RD. Based on seventeen evidence reviews, some of the RD food interventions could be effective, if fully implemented. However, the most effective strategies to improve diet, such as food pricing strategies, restrictions on marketing, and reducing sugar intake, are not reflected in the RD food pledges. Moreover, it was difficult to establish the quality and extent of implementation of RD pledge interventions due to the paucity and heterogeneity of organisations' progress reports. Finally, most interventions reported by organisations seemed either clearly (37\%) or possibly (37\%) already underway, regardless of the RD. Irrespective of the nature of a public health policy to improve nutritional health, pledges or proposed actions need to be evidence-based, well-defined, and measurable, pushing actors to go beyond 'business as usual' and setting out clear penalties for not demonstrating progress (Knai et al 2015).

While voluntary approaches through a PPP modality worked in some places, one review that looked at 18 studies as well a prior review of 14 studies compared the effectiveness of voluntary and mandatory policies to remove trans fats. While voluntary reformulations decreased trans fats by 20 to $38 \%$ and mandatory labelling decreased it by 30 to $74 \%$, bans led to the near elimination of trans fats from the food supply. Additionally, bans were the most equitable, as the other measures led to increased health disparities. For example, both voluntary reformulation and mandatory labelling left more trans fats in cheaper products while mandatory labelling relies on consumers having sufficient nutrition knowledge. The review concluded that bans were the most effective, economical, and equitable (Downs et al. 2017).

In the two years since this study was published, more legislation on trans fats has been passed. The WHO released a plan to remove trans fats from the global food supply by 2023 (WHO 2018b). Bans passed in the United States and Canada in 2018 and Thailand in 2019. Singapore will ban trans fats in 2021. Many more countries and the European Union also passed trans fats regulations that will come into effect in the next two years. However, as of 2019, 110 countries did not have any legislation on trans fats, putting over five million people at risk for exposure (WHO 2019). 
The private sector is widely recognised for being positively engaged in initiatives that tackle nutrition challenges, including through products that treat severely malnourished children, manufacturing nutrient supplements, and fortifying food. However, beyond this limited space, many public health nutrition professionals fear vilification or believe deeply that such cooperation is pointless and potentially unethical. In addition, many business partners also fear vilification or the need to compromise their profit bottom line.

A significant proportion of the lack of trust of the private sector by the public and academic sectors comes from past and current industry transgressions in the nutrition space that continue to threaten the potential for partnerships (Brownell 2012; Freedhoff and Hébert 2011). These transgressions include issues such as "producing profits while disregarding negative social impacts," historic bad behaviour, and continued questionable behaviour among some in the private sector (Haddad 2018; Brownell and Warner 2009). Some private-sector actors have engaged in harmful practices to discourage women from exclusively breastfeeding their children or encourage the consumption of unhealthy junk food around the world through their marketing practices (GHA 2018). Thus, nutrition is particularly rife with historical suspicion, making it incredibly difficult to overcome "bad blood" (19).

One historic example is the consistent disregard for, and violation of, the World Health Assemblyadopted International Code of Marketing Breastmilk Substitutes (16, 9, I12, I14, I16, I18). The Code is meant to protect exclusive breastfeeding of infants younger than six months and to position breastmilk as a complement to other foods for older infants. It is intended to protect mothers, health workers, and the health systems in which they work from commercial promotion of breastmilk substitutes that undermine breastfeeding. "Yet producers in some countries often violate this code, for example by encouraging health facilities to include formula milk in the packs given to new mothers or by offering it free or discounted to pregnant women" (Haddad 2018). A recent Save the Children report found many examples of violations of the Code by some manufacturers of breastmilk substitute (Save the Children 2018). This has led to mistrust of the private sector by the public sector $(12,16,19,112)$. If public health nutrition organisations or individuals do associate with Code violators, they are often regarded by others in the nutrition sectors as complicit with the negative actions of these companies and can be shamed and shunned.

Two interviewees indicated that certain private-sector organisations are accordingly perceived to be a "no go" for engaging with the public sector because of past behaviour with breaking the Code:

"The public nutrition sector doesn't want to work with any of the multinationals that produce infant formula. So most of the dairy-focused industries are not at the table or not accepted to work together. From the public sector, there's a no-go, but at the same time, these companies have never built up a positive collaboration mindset. They are very defensive in nature, and don't have the skills to work in PPPs" (118).

"Well, it [lack of trust] goes back to the behaviour of the formula industries [over the past] several decades, and the pretty clear evidence of the harmful effects of breast milk substitutes on infants and young children. And despite the existence of the code on the regulation of breastmilk substitutes, the industry continues to violate that code 
and countries and organisations just don't have the capacity to properly monitor and enforce and bring to sanction the violators" (I12).

The rampant availability and aggressive advertising of cheap junk food and sugar sweetened beverages (SSBs) that are contributing to poor nutrition and obesity have also been a deterrent to public trust of the private sector (David S. Ludwig and Nestle 2008; G. Sacks et al. 2013; Swinburn et al. 2015; Baker and Friel 2016) $(112,114,116,118)$. The marketing of SSBs, consumption of which increases the risk of obesity and diabetes (Liew 2018; D. S. Ludwig, Peterson, and Gortmaker 2001), to children is unethical (Arie 2019; Boyland and Whalen 2015). "Examples include branding educational materials, embedding advertisements for unhealthy food in computer games, or using toys to market such foods to children in restaurants...Some producers also refuse to take at least some responsibility for the rise in obesity throughout Latin America, Africa and Asia - a trend that correlates with an upswing in the consumption of soft drinks in these regions over the past 15 years" (Haddad 2018; Hawkes 2010; Malik et al. 2010). One respondent noted reservation with PPPs, given the behaviour of 'big food':

"[There is] nervousness about large food companies today and again, the clear evidence of the effect of poor diets on non-communicable diseases and for a long time, the resistance of the food companies to acknowledge the role they are playing. To a large extent, they still try to work around that by placing the blame on individual behaviour and lifestyles and choices rather than the environment that they are helping to create, not only the food environment, but the information and marketing environment around food" (I12).

Whilst some food companies have corporate social responsibility (CSR) initiatives that engage in partnerships with the public sector, there are other aspects of their core business that can simultaneously contradict the missions of CSRs - Box 5 notes some limitations with CSRs. Another respondent reflected on the tactics that such companies have advanced, which have created mistrust and reservations about engaging with these actors:

"Companies will be working with you on the one hand but then lobbying against you on the other. Right? So these companies, especially the big ones ... can be working with their sustainability team and the corporate social responsibility team on an initiative. And then you turn around and their government relations team in Washington DC is up on the Hill [Capitol Hill, seat of the U.S. Congress] trying to kill that piece of legislation that would actually help solve the problem that you're trying to work on with your sustainability team" (116). 


\section{BOX 5. THE CSR “ARM" OF BUSINESS}

PPPs often involve partnering with the CSR arm of a business, rather than the core business itself. CSRs are a type of private business self-regulation that help companies' social responsibility communications and objectives. However, they often pose more as problems than solutions in delivering successful PPPs:

"In our opinion, the reason engagement has moved so slowly is that it has been based too often on a flawed CSR viewpoint. Despite all the hyperbole, CSR tends to be peripheral in most organisations and is not woven into the fabric of the business. It is not always transparent and there may be strings attached.

Sometimes it's driven by a need to buy profile and even worse, CSR has been used as a type of moral counterbalance to practices that have had direct negative impacts on the poor. To make a lasting difference, we believe the prevention of malnutrition must be integrated into the core business of major food companies. Realistically, that requires shareholders to receive a tangible return. At some point, companies must be able to generate profit out of their engagement with the socalled "base of the pyramid" (the economically poorest 1 billion people on our planet). Controversial perhaps, but also rooted in realism" (Collins and Murphy 2013).

Some interviewees mentioned the New York Times' reporting in 2018-2019 on the private sector's push of soda and junk food into emerging economies such as China, Brazil, Ghana, and India. The "Coke Leaks" were a series of emails from executives from Coca-Cola Company confirming that the company was trying to influence, and in some cases derail, nutrition policy in China via the International Life Sciences Institute, which is actually embedded in the public health apparatus in China. There was also the funding by Coca-Cola of the "The Global Energy Balance Network", which paid researchers and academics to put the blame for obesity on a lack of physical activity as opposed to food and beverages. This creates massive mistrust not only in partnerships but in the nutritional science field as a whole (Mozaffarian 2017; Bes-Rastrollo et al. 2013; Bero and Grundy 2018). As one respondent indicated, the trust issue remains hard to overcome, even with some evidence of progress:

"Trust between the stakeholders] is something that's been sorely lacking in the nutrition sector in relation to PPPs for very long, historical reasons. So that's always lurking in the background if not in the foreground and it makes the initial conversation difficult and often things don't go beyond the initial conversation. And it's something that takes a long time to build and is much more quickly destroyed... And I think there's been a softening in some parts of the nutrition community in recent years in part due to organisations like GAIN, in part due to the Scaling Up Nutrition movement. But it's clearly an uneven landscape with respect to that. There's still large and strong pockets of resistance within the nutrition community" (I12).

One respondent noted the difficulties of creating and maintaining trust between the public- and private-sector actors: "There is the challenge of speaking a common language and having trust in 
one another, and that is focused, again, to knowing people on the personal level. How do you build confidence in one another if you've never worked together?" (I18).

As mentioned under factor 1 , the concern of many public health researchers and professionals is the potential conflicts of interest and ethics of engaging with private-sector actors to address obesity and diet-related NCDs in low-, middle- and high-income contexts. It is less so for SMEs addressing undernutrition issues such as stunting or micronutrient malnutrition in low- and middle-income contexts. There is also a concern that governments or civil society organisations that partner with major transnational companies to address an undernutrition challenge will allow that firm to penetrate the emerging market, which may have weak or non-existent government regulatory oversight. Policymakers and advocates forecast that there will be an explosion of ultraprocessed food and beverage products that are widely available and affordable for low-income families due to the rapid expansion of transnational food retailers, manufacturers, and chain restaurants, which will drive an obesity and NCD epidemic within 5-15 years in those countries. This is a consequence of partnering that needs to be part of the assessment of benefits and risks of engagement before an organisation (whether civil society, government, or foundation) decides whether and how to engage.

\section{How to Improve}

To address trust, we need more open discussion of the issues contained in this paper in the format of inclusive meetings, blogs, or viewpoints. We need to start communicating the issues, laying out conflicts of interest, and creating norms of respect for different opinions.

There are many guidelines surrounding conflicts of interest in the nutrition research field regarding when, where, and how to engage with private sector. The WHO's Department of Nutrition and UNSCN have developed tools and hosted consultations to inform for Member States about how to manage nutrition-related partnerships and identify and manage conflicts of interest (WHO 2018). In order to increase trust, not only do partners need to do more good than bad in the food system, but transparency and accountability mechanisms must be in place. Furthermore, parameters of what constitutes a conflict of interest with respect to PPP engagement should be openly articulated, discussed, and documented to widen the safe space for acceptable collaboration.

There is real opportunity to place public and private actors in spaces where they can engage, dialogue, learn, and envision opportunities. There are also opportunities to engage through short courses, panel dialogues, exchange programmes, immersions, and similar approaches. These offer an opportunity to foster dialogue between big and small and between food and non-food private-sector actors to learn their positions, understand their challenges, and find ways to work together. Without listening and engaging, there will be no moving forward.

\section{FACTOR 6: CREATING THE ENABLING ENVIRONMENT}

\section{State of Play}

Governments do not have sufficient insight to exercise the policy levers at their disposal to create a more enabling environment for businesses to do more positive and fewer negative things for public health and nutrition. 
The 2019 Global Syndemic of Obesity, Undernutrition, and Climate Change Lancet Commission report argues that food systems are now made up of powerful commercial interests that promote overconsumption of unhealthy foods on one hand and weak governance and policy inertia by governments and the public sector. The Commission argued that, "In reality, obesity and undernutrition are both driven by the same unhealthy, inequitable food systems, underpinned by the same political economy that is single-focused on economic growth and ignores the negative health and equity outcomes" (Swinburn et al. 2019).

The public sector is meant to implement policies that are driven by and for the public interest with the ultimate goal of benefiting the nutrition and health status of current and future generations (Swinburn et al 2019). Governments should take the lead in developing sound, holistic food system policies, but they often do not, perhaps because of lack of awareness, priorities, or uncertainty of where to take impactful action (Mozaffarian et al 2018). Civil society and nongovernmental organisations should put political pressure on governments to take policy action along with benchmarking progress to encourage both government and business accountability (Swinburn et al 2019).

The Lancet Commission also emphasised that governments should play a substantial role in reducing large commercial interests in policy development processes to enable the implementation of policies that benefit human health. To do this, there is a need to re-design business models to shift focus from short-term, profit-only outcomes to sustainable models that benefit society and the environment. In the report, some guidance is given to the private sector, but the report argues that their role should be in re-orienting markets so that social and environmental aspects of corporate performance are given greater prominence, even equal to financial performance.

The private sector is often not incentivised to engage with governments. Whilst punitive policies, guidelines, and legislation are often necessary to promote positive public health and nutrition outcomes for populations, they often can present themselves as contrary to private sector's profit goals (Haddad 2018; Swinburn et al. 2015, 2019). This very conflict causes public sector entities to approach business with caution, although the potential for the private sector to fill resourcing, capacity, and skill gaps in public health policy provides strong incentives to partner.

An interesting case of incentives (or in this case, disincentives) can be found in the UK sugar levy. Companies were given the guidelines and told they would not be taxed if they reduced the sugar content of beverages. Action by the soft drinks industry to reduce sugar in products and change their product portfolios, coupled with changes in consumer purchasing, has led to a significant reduction in the total volume and per capita sales of sugars sold in soft drinks in the UK. The rate of change accelerated between 2017 and 2018, which also implies that the implementation of the Sugar Drinks Industry Levy acted as an extra incentive for companies to reformulate above and beyond what was already being done as part of voluntary commitments to reformulation, or changes in sales driven by consumer preferences (Bandy et al 2018).

The public sector's lack of influence can also be tied to market forces (Baker and Friel 2016). One respondent below noted that even if governments were to gain power in this domain and create meaningful food-based dietary guidelines and public procurement programmes (Herforth et al. 2019; Herforth and Ahmed 2015; Mozaffarian et al. 2018), fiscal instruments such as taxes on soda 
and unhealthy junk food, or regulations on advertising junk food to children, market forces and consumer demands are still important drivers of change (Swinburn et al. 2015).

Respondents $(12,15,18,19,115)$ noted these market forces of consumer demand, saying:

"I think when we talk about PPPs in the context of nutrition, the first step is to acknowledge that, in fact, public players have very little influence on people's diets and their behaviours" (I10).

"It's not such a controlled or ring-fenced environment. The private sector's doing its thing anyway. Markets are doing their things anyway. And by that, I mean consumers are doing what they want, right? So to say that we're suddenly going to change the way we do things, and now deliver something because we don't have money in public coffers in a different way is kind of disingenuous, because, in fact, you know, whether the public had money in the coffers or not didn't matter. The fact is, consumers are engaging in market-based activities that have big impacts on their nutritional status" (111.)

The "potential benefits of industry-sponsored, healthy lifestyle initiatives include leveraging extensive resources, diverse expertise, and the capacity to reach millions of consumers through diverse marketing channels and media platforms" (Kraak, Kumanyika, and Story 2009). Whilst the private sector has made innovations to promote healthy lifestyles (Bennett, Boles, and Crossley 2007), or improve nutrition (i.e., fortification), very few of their products align with healthy lifestyles and diets, and many food and beverage companies do not align with consumer health (Lang, Rayner, and Kaelin 2006; Wansink and Huckabee 2005).

\section{How to Improve}

There should only be investment where incentive structures are clear. This means that accountability frameworks are established and agreed upon, and independent brokers can mediate. There are a number of standard operating procedures or "ground rules" that partnerships must adopt to improve mutual accountability. The first ground rule is to articulate 'SMART' objectives, define roles, responsibilities and decision rights, and regularly undertake consolidated partnership-wide planning. The second ground rule is the need for a governance mechanism that provides oversight, which includes applying standards for the selection of partners, be they corporate, civil society, or public, establishing systems for managing conflict of interest, and ensuring that basic elements of transparency are observed and enforceable to build trust (Buse and Hammer 2007). Box 6 and Appendix 1 show how to set rules of engagement.

Incentives for PPPs can also be created by de-risking investment in them where alignment of objectives between both sectors are clear and potential positive public health impacts are identified. The small enterprise Dala Foods in Nigeria faced the challenge of producing an affordable and nutritious product for poor consumers and eventually looked to donors to support their efforts through the formation of a PPP (see Appendix 1) (Nwuneli et al 2014).

\section{FACTOR 7: CONNECTING THE DOTS AND FOSTERING DIALOGUE}

\section{State of Play}


Neither public nor private entities fully understand the shared space between sectors or how to engage effectively. A respondent noted the lack of bridging agents, or people who can interface easily with both private and public sectors:

\title{
BOX 6. THE SUN SETS THE RULES OF ENGAGEMENT
}

The Scaling Up Nutrition (SUN) movement has a set of Principles of Engagement for all its members, regardless of sector, which are intended to facilitate collaboration and accountability. At the global level, the movement has set up a Conflict of Interest working group, ethical framework, and tools. Its 'Strategy and Roadmap' also includes a target for countries to approach the prevention and management of conflicts of interest (SUN website; SUN 2016). See Appendix 1 for this case study.

\begin{abstract}
"And so that's where the real art of these PPPs is, it's really at the bridging function. And there aren't that many people out there, practiced at bridging these sectors. They usually come from their own sector, and they reach out into the other one, and theyyou know, they pretend they can talk the talk. But there's very little-there's very few examples of people that actually understand and empathise with the motivations of the various sectors and can serve as a bridging agent" (I10).
\end{abstract}

\section{How to Improve}

An outside broker or "boundary spanner" should manage and evaluate the partnership in an unbiased way, assessing impact whilst identifying actual or potential conflicts of interest that could undermine the partnership. This actor should establish an evaluation plan with adequate support and independence to report progress on key metrics internally and externally. Successful partnerships will, in many cases, require a re-evaluation of the partner organisation in terms of transparency, accountability, and forthrightness in defining expectations both of itself and of its partners (Mitchell 2008). Building on Hawkes and Buse's (2011) point about the need for "shared decision-making power", this co-creation should extend into shared identification of evaluation metrics, with guidance from an independent third-party evaluator. In order to increase the likelihood of success, what it looks like needs to be jointly articulated, understood, and agreed upon by all involved parties.

\section{FACTOR 8: BRINGING EQUAL RESOURCES TO THE TABLE}

\section{State of Play}

Resources are a significant challenge in PPPs. Resources are not just financial, but also human and institutional capacity and technical know-how. With PPPs, there are significant resources often brought to the table by the private sector, and they are often seen to provide that service across many sectors (Roehrich, Lewis, and George 2014). This inevitably creates an imbalanced dynamic of resources and power. 
Whilst initial investment may not be a serious impediment in initiating the PPP, timely disbursement of funds and recurring costs can be challenging (FAO 2016). The PPP mechanism is inherently designed to address the issue of affordability by pooling resources from various sources to overcome the limited funding available in the public sector, which often brings in-kind contributions to the table. However, with any partnership, there is a tendency to value tangible financial resources compared to intangible resources such as capacities, expertise, or networksand hence partners committing the greatest financial resources tend to have higher bargaining power (Save the Children, 2017).

"So once you have established something that on paper could work, who takes responsibility for the project management and almost has a neutral project management mentality and skill to provide it? It's not always the private sector or the public sector party that are capable of doing that" (I18).

There is also a challenge of technical capacity from both public and private sides (11, 19. I10, I14, 118). A large number of informal or small-scale players in the private sector do not have the technical know-how or human resources capacity to effectively engage in the partnership and deliver on the agreed-upon goals (IDS 2018; Glopan 2018). One interviewee expressed concern for SMEs: "Smaller, medium-sized enterprises—I think they are willing but haven't necessarily the capacity or the know-how, how to work it" (118).

Nevertheless, fortification and supplementation programmes have multiple examples of where SMEs have successfully developed partnerships with the public sector (Hoddinott 2015); these should be studied further for lessons that can be applied to other aspects of PPPs. Some of the case studies included in Appendix 1 include such SMEs PPPs. However, as with most such studies, evidence is focused on outputs and outcomes, rather than on how the partnership was resourced, structured, governed, and managed.

Another respondent noted the lack of capacity and appropriate tactics for public-sector actors to engage with the private sector:

"The food and beverage industry are an incredible power. Not only economic, but political power. So can you have dinner with the devil? Well, you need to really have your tools, to defend from what they are going to do to you. So, probably, there's a perception that we don't have those tools" (114).

\section{How to Improve}

PPPs must be adequately resourced to prosper and be sustainable. Financing gaps can be minimised through setting more realistic goals and ensuring that plans identify specific partners to plug gaps. Financial, technical, and in-kind support must be clearly quantified by each partner. Partners must also acknowledge the real costs of PPP management and agree on how to finance them (Kent Buse and Harmer 2007).

Karaki (2016) argues that PPPs demand significant time and resources and stakeholders involved in these partnerships need to dedicate adequate time and financial and human resources to support their success. Save the Children's analysis (Save the Children \& European Center for Development Policy Management, 2017) of PPPs in nutrition highlights that PPPs may require different types of resources, including networks, political connections, and expertise along with 
financial resources in an iterative way as the partnership continues or grows. Box 7 shows examples of establishing common goals and rules.

Other sectors, such as agriculture and infrastructure, also show that historically, private-sector partners brought financing to complement public-sector financing and allowed projects to go forward that otherwise would have been discarded due to fiscal constraints. The financing also created an incentive mechanism to align private and public interests (Alonso-Conde, Brown, and Rojo-Suarez 2007). However, some private-sector organisations can find financing PPPs risky. It is difficult across many PPPs to guarantee "value for money" and difficult to guarantee it is the best option for achieving the objectives of the partnership (FAO 2016).

\section{THE MEASURES OF SUCCESS}

In this section, we highlight two measures of success that influence PPPs' impact on public health nutrition goals. The factors, the current state of play, and what could be improved to address these factors are summarised in Table 2 above and expanded upon below.

\section{BOX 7. SETTING GOALS AND PUTTING FINANCING ON THE TABLE}

The DSM-WFP partnership, mentioned previously, established and continues to revisit shared goals and objectives. Established in 2007, the partnership has been based on a series of memoranda of understanding, with each building on the achievements of the previous through joint identification of objectives from both partners. Furthermore, each phase of the partnership included dedicated financial, product, and service resourcing and shared management of projects (R4D 2015). A 10-year strategic engagement between Cargill and CARE also demonstrates the value of a phased long-term partnership that continually evaluates and builds upon the learning from earlier phases. See Appendix 1 for this case study. A partnership between the Grameen Foundation and Danone in Bangladesh in 2006 provides another example of a PPP with an alignment of goals between the partners along with the leveraging of individual strengths and capacities of each. However, even with these fundamental factors in order, this PPP initially suffered losses, as it did not have a thorough understanding of the behaviours and preferences of its target marketing network (rural saleswomen) and consumers (the rural poor). The resultant lack of resources to reinvest in this social enterprise model required the partners to revisit and redesign the model. See Appendix 1 for this case study.

\section{FACTOR 9: ESTABLISHING GOALS AND PROCESSES TO ACHIEVE THEM}

\section{State of Play}

Goals are often not aligned within PPPs because not all parties are clear on the intended processes and outcomes, not all have a perception of equitable 'skin in the game', and not all have minimal conflicts of interest. 
There is extensive literature citing the importance of goal alignment and clarity in PPPs, and many of the interviewees mentioned this as a challenge $(12,14,16,17,112,114,115,118,119)$. Inherently, the public sector comes to the table with public health goals in mind, and the private sector with profit-making objectives. Identification of specific shared objectives amidst these two apparently conflicting aims is key. As discussed earlier, there is mistrust from parts of the public sector of the private sector. Many companies also fear criticism of their motives in attempting to operate commercially (Collins and Murphy 2013).

"Depending on which nutrition scientists are in the room, in the case of the governance mechanisms, it's not even clear that you can get agreement [about goals] among the nutritionists" (112).

"I find myself wanting there to be a firm contract and set of agreements in hand that are measurable and enforceable. Only then could both sides proceed or especially only then would the nutrition community or members of it proceed. Absent that kind of formal agreement, I don't think that this mistrust issue can be overcome" (I12).

As mentioned several times in this paper, there is also a fear of potentially introducing conflicts of interest and reputational risks through engagement; this impacts many of the factors outlined in this paper. Some of those interviewed found this to be a major barrier to goal alignment (12, 16, $113,114,116)$. This issue is particularly acute in the nutrition research community, where industry has funded research that benefits their products and bottom line and is not aligned to public health research interests (Nestle 2013). One respondent compared this conflict of interest to the health sector's relationship with pharmaceutical companies:

"In nutrition, it feels like we're still at a stage when everybody is kind of afraid of, especially from the public side, afraid of conflicts of interest rather than saying that's the way it is. And we're just going to be very pragmatic in how we approach that because food is coming almost entirely from the private sector and there is no way around it. Comparing the health sector to the nutrition sector, there is really quite a gap in the way public sector interacts with businesses" (I3).

\section{How to Improve}

Once it has been established that a partnership is essential as opposed to "going it alone," there are several publications that have summarised what makes partnerships successful, including Buse and Walt (2002) and the Institute of Medicine's Building Public-Private Partnerships in Food and Nutrition (2012).

Key success factors include:

- Have clearly specified, realistic, and shared goals, roles, and responsibilities

- Establish a sense of authentic trust and respect

- Plan jointly and early, and put in place project management processes

- Lay out distinct benefits for all parties, with unique resource contributions

- Acknowledge the real costs of PPP management and agree on how to finance them

- Formulate clear procedural steps for risk mitigation

- Ensure equality of participation and active maintenance of the partnership

- Agree on obligations through transparent modes of working and reporting 


\section{FACTOR 10: PUTTING IN PLACE ROBUST ACCOUNTABILITY MECHANISMS}

\section{State of Play}

Much of the literature (Drewnowski et al. 2018; Swinburn et al. 2015; Eggersdorfer and Bird 2016; Kraak et al. 2014; DiMartino and Scott 2013; International Food Policy Research Institute (IFPRI) 2015) and interviews note insufficient accountability and transparency mechanisms (14, 16, 18, 19, $112,115)$. The concept of accountability is linked to institutional performance, encompassing two factors that influence decision making:

1. Answerability, which involves key actors providing an account of their decision and actions to relevant stakeholders using a trusted, transparent, responsive, credible, and inclusive process that provides meaningful and verifiable information (Swinburn et al. 2015); and

2. Enforceability, which involves key actors complying with established standards, codes of conduct, and receiving penalties or restrictions when they do not deliver on their pledges, commitments, and obligations (Kraak and Story 2010).

What is most striking is the emphasis both place on transparency and accountability and on a common understanding between the parties of what is expected. The implication of these factors is that successful partnerships will frequently require a re-evaluation of the private-sector partner in terms of transparency, accountability, and forthrightness in defining expectations both of itself and of its partners (Mitchell 2008). Without strong and independent accountability structures, governments are unlikely to implement actions to manage the power imbalances that often come with PPPs (Kraak et al. 2014).

Answerability and enforceability apply to all sectors, in addition to business, and enable all stakeholders to assess the willingness and capacity of potential partners to tackle malnutrition. Amongst other indicators, the Global Nutrition Reports 2014-2018 tracked self-reported progress toward commitments made at the Nutrition for Growth Summit in 2013. These financial and nonfinancial (impact, policy, and programmatic) commitments were made by donors, countries, civil society organisations, private sector entities, UN agencies, and other parties. However, analyses of these commitments identify multiple challenges, including a widespread lack of SMART commitments and low survey response rates, particularly amongst business (IFPRI 2015 \& 2016; DI 2017).

One example of an independent private-sector nutrition accountability mechanism is the Access to Nutrition Index (ATNI). This benchmarking methodology ranks the world's largest food and beverage companies on their "nutrition- focused commitments, practices and performance globally" (ATNI 2016). This can provide a starting point for public-sector entities to assess these companies' suitability to partner based on their nutrition policies, product profiles, and marketing. The International Network for Food and Obesity/Non-communicable Diseases Research, Monitoring, and Action Support (INFORMAS) is another such accountability mechanism. A network of organisations and researchers in over 35 countries, it aims to "monitor, benchmark and support public and private sector actions to increase healthy food environments and reduce obesity and NCDs and their related inequalities." It also communicates progress made by countries on improving food environments and uses these results to translate evidence into public- and private-sector actions (INFORMAS website, accessed March 2020) (Sacks et al. 2019). 
Another element of accountability in PPPs is representation, referring to who is in the room and whose voice is being heard (or not heard). In particular, one respondent noted a lack of engagement with civil society:

"There is a lack of understanding about how we engage civil society who are not nonstate actors, the private sector actors, and their perspectives can help add some accountability, perspective, and sometimes evidence in terms of how policies should be designed and the actual impacts of those policies" (I15).

\section{How to Improve}

Whilst there remains little evidence that joined efforts improve nutrition and diets, it is thought that partnership could have a positive effect, if transparency, public accountability, and management of conflicts of interest are in place (Swinburn et al. 2015):

"Whereas responsibility refers to the obligations to be fulfilled by one actor, accountability involves one actor answering to another actor, the account holder, who is empowered with the authority to assess how well the former fulfils obligations to achieve specific goals. Accountability also involves recognition of achievements and enforcement of performance through the application of sanctions for poor performance or non-compliance. As such, accountability is ultimately about governance and power and determines how and why decisions are made, who makes decisions, how power is used, shared, and balanced, whose opinions are important, and who holds whom to account" (Swinburn et al. 2019).

"Government and business engagement to advance the nutrition goals will require processes that are transparent, open, and inclusive; where all actors operate with accountability, integrity and mutual respect. While engagement should not compromise any individual organization's independence or reputation, governments and businesses acknowledge that their interdependence and mutual accountability in the service of the nutrition goals will frequently require joint but de-conflicted work processes. As noted above, more needs to be done to establish clear mechanisms to define and measure engagement, but transparent reporting and accountability are fundamental, as is clear compliance with established policies." (GAIN USCIB, 2018)

Kraak and colleagues established an accountability framework to promote healthy food environments, which can be applied to public health nutrition goals (Kraak et al 2012; Swinburn et al 2015). At the core of this framework is agreement on objectives, processes, and outcomes. The first step of the accountability cycle is to 'take the account' through the measurement of progress towards agreed goals. One of the best ways to do this is through an independent body. The second step of the accountability framework is to 'share the account,' which involves wide dissemination of progress made by partners in the partnership in the implementation and meeting of targets, for example, the Sustainable Development Goal 2 or the World Health Assembly nutrition targets. This should be done by the research partner. The third step is to 'hold the account,' in which partners acknowledge the achievements and sanction the poor performance of other partners. This should be done by governments, and CSOs for governments. The fourth step of the accountability framework aims to ensure a 'response to the account' and involves changes in policies and practices by governments and all partners. 
The framework was then used to examine the International Food \& Beverage Alliance's (IFBA) adoption of the Global Policy on Marketing Communications to Children (Kraak et al 2019). They evaluated 12 food manufacturers, which had a combined portfolio of US $\$ 369$ billion dollars in global food and beverage sales in 2017, with nine firms operating businesses in 100 to 200 countries.

Their evaluation showed that the UN Secretary General or WHO Director General failed to appoint an independent and empowered body with adequate authority, resources, and a clear charge to develop goals and performance metrics to evaluate the alignment of IFBA's Global Policy with the Resolution WHA63.14 by October 2018. This step is critical to ensure accountability from the outset because industry actors may develop weaker nutrition guidelines or standards compared with those developed by national government and civil society actors. They also found that there was less progress made on establishing benchmarks, goals, and performance targets by an external appointed body or "taking the account", as well as "sharing the account" in that there was no evidence to suggest that a UN System body had engaged stakeholders through a deliberative process to discuss the credibility and alignment of IFBA's Global Policy with best-practice recommendations to support the 2010 Resolution WHA63.14 and responsible marketing to children up to age 18 years. There was no evidence of "holding the account" because no progress had been made by an empowered body to hold IFBA firms accountable for its Global Policy and marketing practices that did not meet WHO and other best practice recommendations. Lastly, there was no evidence on "responding to the account" because of the lack of evidence that there was any progress made by any actor to strengthen accountability structures to compel IFBA to align their Global Policy with best practice recommendations during the review period.

Accountability trackers such as the INFORMAS Business Impact Assessment tool, the Access to Nutrition Index, the Global Nutrition Report's Nutrition for Growth (N4G) tracking, and the World Benchmarking Alliance tracking on the food-agri sector are all important initiatives that put accountability at the front and centre and publicly show progress on commitments.

\section{CONCLUSION}

Multi-stakeholder partnerships and engagements, including PPPs, combine resources and expertise of different stakeholders and may be able to address complex issues that cannot easily be solved by a single actor. These partnerships were identified in SDG17 as a central tool in the implementation of the 2030 Agenda.

As with other types of PPPs, food system-specific PPPs for diets and nutrition present an opportunity to leverage the strengths and contributions of each partner for a shared socioeconomic development output. However, in nutrition the opportunities that exist are not being identified, seized, or measured. We find this is due to: the varied current state of play for is due to insufficient evidence; the perceived intractability of some of malnutrition's causes and solutions; a pervasive lack of trust; an unwillingness to engage; and missing or insufficient accountability mechanisms, goal alignment, and resources. However, it is this very multifaceted nature of nutrition and the diversity of actors that contribute to it within the food system that make partnerships ripe for consideration and careful examination.

This paper does not unconditionally advocate for PPPs as the solution for fixing the many problems of malnutrition within the food system, although it does advocate for not ignoring them 
as a potential solution. It proposes considered and cautious reflection on the 10 factors that contribute to the motivation, means, and measures of success for a PPPs. An examination of the status of each of these factors indicates there is a need for much more work to have all three types of factors in place. Four key themes emerge amongst the recommendations:

Strengthen the evidence base. Parties that have an impact on public health nutrition outcomes should have a wealth of evidence to inform whether and how they embark on PPPs. More thirdparty evidence is needed to illustrate where working collaboratively between the private and public sectors can achieve more for both parties and public health goals than working separately. Such evaluations would also demonstrate the track records of private-sector entities, highlighting those with the greatest potential to be a credible partner. It is also important to document partnership processes, including how they are resourced, structured, governed, and managed, to enable greater learning. On a technical level, more evidence is also needed to identify clear causal pathways for determining solutions to specific nutritional problems. How this evidence base should be built is another challenge. Assessing the impact of these partnerships needs a mix of different types of evaluations. Some should assess the impact on diet and nutrition outcomes, but studies should also assess the effectiveness of PPPs and their ability to produce measurable outcomes and impacts as well as the financial flows, resource contributions, and alignment outcomes of the partnerships themselves.

Address the trust deficit and conflicts of interest head on. There are historic and deeply entrenched perceptions of various stakeholders in this space. Develop trust through strengthening the evidence base (as above); building transparent systems and accountability frameworks such as a public registry of PPPs; encouraging open discussion and dialogue around shared objectives, conflicts of interest, and safe spaces to collaborate without negative repercussions of engagement. In some instances, involvement of a third-party broker, without the entrenched biases of the public or private sector, can help to facilitate such partnerships and further encourage trust to grow. It is important to focus on the "sweet spot" where partnerships are most likely to thrive, improving the likelihood of success, as well as further building confidence that PPPs have the potential to deliver on public health nutrition goals.

Create the right structures and incentives. Governments should create appropriate incentives for the private sector to positively engage on public health nutrition goals, along with disincentives for contributing to negative outcomes. Public, private, and donor funders should introduce financial de-risking measures to encourage the formation of potentially successful PPPs that would otherwise not have the resources to exist. It is important to understand and value both financial and non-financial partner contributions to redress the power imbalances that often favour the private sector. Actors should also ensure that shared objectives across partners are aligned and that each party has an equitable stake in collective success. Lastly, it will be necessary to develop fit-for-purpose tools to guide and evaluate PPPs, further corroborating the evidence base for food system-specific PPPs for diets and nutrition.

Think creatively. When forming PPPs, partners from the food- and non-food systems should be considered. It is important to enlist participation from civil society and academia to strengthen accountability, evidence, and learning. Partners should also adapt existing accountability frameworks to suit the complexities of collaboration on nutrition within the food system. They can learn from the successes and challenges of other sectors that have a more robust history of using 
PPPs to achieve social development outcomes. Finally, it is essential to not let any potential solution go unexplored to accelerate the reduction in malnutrition. 


\section{REFERENCES}

Afshin, Ashkan, José L. Peñalvo, Liana Del Gobbo, Jose Silva, Melody Michaelson, Martin O'Flaherty, Simon Capewell, Donna Spiegelman, Goodarz Danaei, and Dariush Mozaffarian. 2017. "The Prospective Impact of Food Pricing on Improving Dietary Consumption: A Systematic Review and Meta-Analysis." PloS One 12 (3): e0172277.

Afshin, Ashkan, Patrick John Sur, Kairsten A. Fay, Leslie Cornaby, Giannina Ferrara, Joseph S. Salama, Erin C. Mullany, et al. 2019. "Health Effects of Dietary Risks in 195 Countries, 19902017: A Systematic Analysis for the Global Burden of Disease Study 2017." The Lancet, April. https://doi.org/10.1016/S0140-6736 (19)30041-8.

Alderman, Harold H.; Elder, Leslie K.; Goyal, Aparajita; Herforth, Anna Whitson; Hoberg, Yurie Tanimichi; Marini, Alessandra; Ruel Bergeron, Julie; Saavedra Chanduvi, Jaime; Shekar, Meera; Tiwari, Sailesh; Zaman, Hassan. 2013. Improving nutrition through multisectoral approaches (English). Improving nutrition through multisectoral approaches. Washington DC : World Bank Group.

http://documents.worldbank.org/curated/en/625661468329649726/Improving-nutritionthrough-multisectoral-approaches

Alonso-Conde, Ana Belen, Christine Brown, and Javier Rojo-Suarez. 2007. "Public Private Partnerships: Incentives, Risk Transfer and Real Options." Review of Financial Economics 16 (4): 335-49.

Arie, Sophie. 2019. "WHO Calls for More Action to Protect Children from Online Junk Food Advertising." BMJ. https://doi.org/10.1136/bmj.11221.

Austin, James E. 2000. "Strategic Collaboration Between Nonprofits and Businesses." Nonprofit and Voluntary Sector Quarterly 29 (1_suppl): 69-97.

Austin, James, and Arthur McCaffrey. 2002. "Business Leadership Coalitions and PublicPrivate Partnerships in American Cities: A Business Perspective on Regime Theory." Journal of Urban Affairs 24 (1): 35-54.

Baker, Phillip, and Sharon Friel. 2014. "Processed Foods and the Nutrition Transition:

Evidence from Asia." Obesity Reviews: An Official Journal of the International Association for the Study of Obesity 15 (7): 564-77.

Balarajan, Yarlini, and Michael R. Reich. 2016. "Political Economy Challenges in Nutrition." Globalization and Health 12 (1): 70.

Bandy et al. 2020. Reductions in sugar sales from soft drinks in the UK from 2015 to 2018. BMC Medicine. https://doi.org/10.1186/s12916-019-1477-4

Bennett, Jonathan, Olive Boles, and Rachel Crossley. 2007. A Recipe for Success: How Food Companies Can Profit from Consumer Health. IBLF.

Bero, Lisa, and Quinn Grundy. 2018. "Conflicts of Interest in Nutrition Research." JAMA. https://doi.org/10.1001/jama.2018.5662.

Bes-Rastrollo, Maira, Matthias B. Schulze, Miguel Ruiz-Canela, and Miguel A. MartinezGonzalez. 2013. "Financial Conflicts of Interest and Reporting Bias Regarding the Association between Sugar-Sweetened Beverages and Weight Gain: A Systematic Review of Systematic Reviews." PLoS Medicine 10 (12): e1001578.

Boyland, Emma Jane, and Rosa Whalen. 2015. "Food Advertising to Children and Its Effects on Diet: Review of Recent Prevalence and Impact Data." Pediatric Diabetes.

https://doi.org/10.1111/pedi.12278. 
Brownell, Kelly D. 2012. "Thinking Forward: The Quicksand of Appeasing the Food Industry." PLoS Medicine 9 (7): e1001254.

Brownell, Kelly D., and Kenneth E. Warner. 2009. "The Perils of Ignoring History: Big Tobacco Played Dirty and Millions Died. How Similar Is Big Food?" The Milbank Quarterly 87 (1): 25994.

Bryce, Jennifer, Denise Coitinho, lan Darnton-Hill, David Pelletier, and Per Pinstrup-Andersen. 2008. "Maternal and Child Undernutrition: Effective Action at National Level." The Lancet. https://doi.org/10.1016/s0140-6736 (07)61694-8.

Buse, K., and G. Walt. 2000. "Global Public-Private Partnerships: Part I--A New Development in Health?" Bulletin of the World Health Organization 78 (4): 549-61.

Buse, Kent, and Andrew M. Harmer. 2007. "Seven Habits of Highly Effective Global Publicprivate Health Partnerships: Practice and Potential." Social Science \& Medicine 64 (2): 25971.

Buse, Kent, and Gill Walt. 2002. "Globalisation and Multilateral Public-Private Health Partnerships: Issues for Health Policy." Health Policy in a Globalising World, 41-62.

Carmen Casanovas, Ma del, Chessa K. Lutter, Nune Mangasaryan, Robert Mwadime, Nemat Hajeebhoy, Ana Maria Aguilar, Ciro Kopp, et al. 2013. "Multi-Sectoral Interventions for Healthy Growth." Maternal \& Child Nutrition 9: 46-57.

Chen, Stephen. 2018. "Multinational Corporate Power, Influence and Responsibility in Global Supply Chains." Journal of Business Ethics: JBE 148 (2): 365-74.

Clapp, J., and S. R. Isakson. 2018. "Risky Returns: The Implications of Financialization in the Food System." Development and Change.

https://onlinelibrary.wiley.com/doi/abs/10.1111/dech.12376

Clapp, Jennifer. 2017. "Concentration and Power in the Food System: Who Controls What We Eat?Howard, Philip H. 2016. Concentration and Power in the Food System: Who Controls What We Eat? New York: Bloomsbury Academic." Global Environmental Politics.

https://doi.org/10.1162/glep_r_00423.

Curtis, Val, Wolf Schmidt, Stephen Luby, Rocio Florez, Ousmane Touré, and Adam Biran. 2011. "Hygiene: New Hopes, New Horizons." The Lancet Infectious Diseases 11 (4): 312-21.

Darnton-Hill, lan, and Samir Samman. 2015. "Challenges and Opportunities in Scaling-Up Nutrition in Healthcare." Healthcare (Basel, Switzerland) 3 (1): 3-19.

De Costa, Ayesha, Eva Johansson, and Vinod K. Diwan. 2008. "Barriers of Mistrust: Public and Private Health Sectors' Perceptions of Each Other in Madhya Pradesh, India." Qualitative Health Research 18 (6): 756-66.

DiMartino, Catherine, and Janelle Scott. 2013. "Private Sector Contracting and Democratic Accountability." Educational Policy. https://doi.org/10.1177/0895904812465117.

Drewnowski, Adam, Benjamin Caballero, Jai K. Das, Jeff French, Andrew M. Prentice, Lisa R. Fries, Tessa M. van Koperen, Petra Klassen-Wigger, and Barbara J. Rolls. 2018. "Novel Public-Private Partnerships to Address the Double Burden of Malnutrition." Nutrition Reviews 76 (11): 805-21.

Dukeshire, Steven. 2013. "Concentration, Consolidation, and Control: How Big Business Dominates the Food System." Journal of Agriculture, Food Systems, and Community Development. https://doi.org/10.5304/jafscd.2013.041.010.

Dunford, Elizabeth K., Cliona Ni Mhurchu, Liping Huang, Stefanie Vandevijvere, Boyd Swinburn, Igor Pravst, Lizbeth Tolentino-Mayo, Marcela Reyes, Mary L'Abbe, and Bruce C. 
Neal. 2019. "A Comparison of the Healthiness of Packaged Foods and Beverages from 12 Countries Using the Health Star Rating Nutrient Profiling System, 2013-2018." Obesity Reviews: An Official Journal of the International Association for the Study of Obesity 386 (July): 2287.

Eggersdorfer, Manfred, and Julia K. Bird. 2016. "How to Achieve Transparency in PublicPrivate Partnerships Engaged in Hunger and Malnutrition Reduction." World Review of Nutrition and Dietetics 115 (May): 224-32.

Fanzo, J., P. Pronyk, A. Dasgupta, M. Towle, and V. Menon. n.d. "An Evaluation of Progress toward the Millennium Development Goal One Hunger Target: A Country-Level, Food and Nutrition Security Perspective." Academia.edu.

http://www.academia.edu/download/44715585/An_Evaluation_of_Progress_Toward_the_Mil 20160413-23043-1rhl4t8.pdf.

Fanzo, Jessica, and Rebecca McLaren. 2019. "An Overview of the Ethics of Eating and Drinking." Handbook of Eating and Drinking. https://doi.org/10.1007/978-3-319-75388-1_821.

Ferroni, Marco, and Paul Castle. 2011. "Public-Private Partnerships and Sustainable Agricultural Development." Sustainability: Science Practice and Policy 3 (7): 1064-73.

Food and Agriculture Organization of the United Nations, United Nations International Children's Emergency Fund, World Health Organization, World Food Programme, and International Fund for Agriculture Development. 2018. The State of Food Security and Nutrition in the World 2018: Building Climate Resilience for Food Security and Nutrition. Food \& Agriculture Organization of the United Nations.

Food and Agriculture Organization of the United Nations. 2018. Nutrition and Food Systems: A Report by the Night Level Panel of Experts on Food Security and Nutrition of the Committee on World Food Security. September 2017. Food \& Agriculture Org.

Food Standards Australia and New Zealand. Review Report. Trans Fatty Acids in the New Zealand and Australian Food Supply. July 2009.

http://www.foodstandards.gov.au/_srcfiles/TFAs_Aus_NZ_Food\%20.Supply.pdf.

Food Standards Australia and New Zealand. Roundtable on trans fats in the quick service restaurant industry - report on survey of progress of voluntary initiatives to reduce trans fatty acids in the Australian Food Industry Supply. July 2009.

http://www.health.gov.au/internet/main/

publishing.nsf/Content/F5F93016C243672FCA2578A20019F090/\$File/Trans-Fatty-Acids-inthe-Australia-and-New-Zealand-Food-Supply\%20-\%20Att3.pdf.

Forouzanfar, Mohammad H., Ashkan Afshin, Lily T. Alexander, H. Ross Anderson, Zulfigar A. Bhutta, Stan Biryukov, Michael Brauer, et al. 2016. "Global, Regional, and National Comparative Risk Assessment of 79 Behavioural, Environmental and Occupational, and Metabolic Risks or Clusters of Risks, 1990--2015: A Systematic Analysis for the Global Burden of Disease Study 2015." The Lancet 388 (10053): 1659-1724.

Freedhoff, Yoni, and Paul C. Hébert. 2011. "Partnerships between Health Organizations and the Food Industry Risk Derailing Public Health Nutrition." CMAJ: Canadian Medical Association Journal = Journal de l'Association Medicale Canadienne 183 (3): 291-92.

Fuchs, Doris, Agni Kalfagianni, and Maarten Arentsen. 2009. "Retail Power, Private Standards, and Sustainability in the Global Food System." Corporate Power in Global Agrifood Governance, 29-59.

Garrett, James L., and Marcela Natalicchio. 2010. Working Multisectorally in Nutrition: Principles, Practices, and Case Studies. Intl Food Policy Res Inst. 
Gillespie, Stuart, Lawrence Haddad, Venkatesh Mannar, Purnima Menon, Nicholas Nisbett, and Maternal and Child Nutrition Study Group. 2013. "The Politics of Reducing Malnutrition: Building Commitment and Accelerating Progress." The Lancet 382 (9891): 552-69.

Global Alliance for Improved Nutrition \& the USCIB Foundation. 2018. "No More Missed Opportunities: Advancing Public-Private Partnerships to Achieve the Global Nutrition Goals"

Glopan. 2018. "Improving Diets in an Era of Food Market Transformation: Challenges and Opportunities for Engagement between the Public and Private Sectors. Policy Brief No. 11. London, UK: Global Panel on Agriculture and Food Systems for Nutrition."

GSMA, n.d. https://www.gsma.com/mobilefordevelopment/mhealth/mnutrition/ Accessed $18 / 01 / 2020$

Haddad, Lawrence. 2018. "Reward Food Companies for Improving Nutrition." Nature 556 (7699): 19-22.

Hall, Kevin D. n.d. "Ultra-Processed Diets Cause Excess Calorie Intake and Weight Gain: A One-Month Inpatient Randomized Controlled Trial of Ad Libitum Food Intake."

https://doi.org/10.31232/osf.io/w3zh2.

Hamann, Ralph, Stephanie Giamporcaro, David Johnston, and Schirin Yachkaschi. 2011. "The Role of Business and Cross-Sector Collaboration in Addressing the 'wicked Problem' of Food Insecurity." Development Southern Africa 28 (4): 579-94.

Hawkes, Corinna, and Kent Buse. 2011. "Public Health Sector and Food Industry Interaction: It's Time to Clarify the Term 'Partnership' and Be Honest about Underlying Interests."

European Journal of Public Health 21 (4): 400-401.

Hawkes, Corinna. 2010. "The Worldwide Battle against Soft Drinks in Schools." American Journal of Preventive Medicine 38 (4): 457-61.

Herforth, Anna, and Selena Ahmed. 2015. "The Food Environment, Its Effects on Dietary Consumption, and Potential for Measurement within Agriculture-Nutrition Interventions." Food Security 7 (3): 505-20.

Herforth, Anna, Mary Arimond, Cristina Álvarez-Sánchez, Jennifer Coates, Karin Christianson, and Ellen Muehlhoff. 2019. "A Global Review of Food-Based Dietary Guidelines." Advances in Nutrition, April. https://doi.org/10.1093/advances/nmy130.

Herrick, Clare. 2009. "Shifting Blame/selling Health: Corporate Social Responsibility in the Age of Obesity." Sociology of Health \& Illness 31 (1): 51-65.

Hoddinott, J., S. Gillespie, and S. Yosef. 2016. "Public-Private Partnerships and Undernutrition: Examples and Future Prospects." In , 115:233-38.

Hoddinott, John F., Stuart Gillespie, and Sivan Yosef. 2015. Public-Private Partnerships and the Reduction of Undernutrition in Developing Countries. Intl Food Policy Res Inst.

Hodge, Graeme A., Carsten Greve, and Anthony E. Boardman. 2010. "Introduction: The PPP Phenomenon and Its Evaluation." Chapters.

https://ideas.repec.org/h/elg/eechap/13451_1.html.

Hurlimann, Thierry, Juan Pablo Peña-Rosas, Abha Saxena, Gerardo Zamora, and Béatrice Godard. 2017. "Ethical Issues in the Development and Implementation of Nutrition-Related Public Health Policies and Interventions: A Scoping Review." PloS One 12 (10): e0186897.

Initiatives, Development. 2018. "2018 Global Nutrition Report: Shining a Light to Spur Action on Nutrition." Development Initiatives Bristol, UK.

Institute of Medicine (US). 2012. Building Public-Private Partnerships in Food and Nutrition: Workshop Summary. Washington (DC): National Academies Press (US). 
International Food Policy Research Institute (IFPRI). 2015. Synopsis: Global Nutrition Report 2015: Actions and Accountability to Advance Nutrition and Sustainable Development. Intl Food Policy Res Inst.

Jerling, Johann, David Pelletier, Jessica Fanzo, and Namukolo Covic. 2016. "Supporting Multisectoral Action: Capacity and Nutrition Leadership Challenges Facing Africa." Achieving a Nutrition Revolution for Africa: The Road to Healthier Diets and Optimal Nutrition. Washington DC: International Food Policy Research Institute (IFPRI), 147-69.

Kaan, Christopher, and Andrea Liese. 2011. "Public Private Partnerships in Global Food Governance: Business Engagement and Legitimacy in the Global Fight against Hunger and Malnutrition." Agriculture and Human Values 28 (3): 385-99.

Kickbusch, I., and J. Quick. 1998. "Partnerships for Health in the 21st Century." World Health Statistics Quarterly. Rapport Trimestriel de Statistiques Sanitaires Mondiales 51 (1): 68-74.

Knai C, James L, Petticrew M, Eastmure E, Durand MA, Mays N. An evaluation of a publicprivate partnership to reduce artificial trans fatty acids in England, 2011-16. Eur J Public Health. 2017;27 (4):605-608. doi:10.1093/eurpub/ckx002

Knai, C., Petticrew, M., Durand, M.A., Eastmure, E., James, L., Mehrotra, A., Scott, C. and Mays, N., 2015. Has a public-private partnership resulted in action on healthier diets in England? An analysis of the Public Health Responsibility Deal food pledges. Food policy, 54, pp.1-10.

Kraak, V., 2012. Food supplies. Trans fats. Government policies and actions to protect citizen health. World Nutrition, 3 (8).

Kraak, Vivica I., and Mary Story. 2010. "A Public Health Perspective on Healthy Lifestyles and Public-Private Partnerships for Global Childhood Obesity Prevention." Journal of the American Dietetic Association 110 (2): 192-200.

Kraak, Vivica I., Boyd Swinburn, Mark Lawrence, and Paul Harrison. 2014. "An Accountability Framework to Promote Healthy Food Environments." Public Health Nutrition 17 (11): 246783.

Kraak, Vivica I., Paige B. Harrigan, Mark Lawrence, Paul J. Harrison, Michaela A. Jackson, and Boyd Swinburn. 2012. "Balancing the Benefits and Risks of Public-Private Partnerships to Address the Global Double Burden of Malnutrition." Public Health Nutrition 15 (3): 503-17.

Kraak, Vivica I., Shiriki K. Kumanyika, and Mary Story. 2009. "The Commercial Marketing of Healthy Lifestyles to Address the Global Child and Adolescent Obesity Pandemic: Prospects, Pitfalls and Priorities." Public Health Nutrition 12 (11): 2027-36.

Kraak, Vivica I., Sofia Rincón-Gallardo Patiño, and Gary Sacks. 2019. "An Accountability Evaluation for the International Food \& Beverage Alliance's Global Policy on Marketing Communications to Children to Reduce Obesity: A Narrative Review to Inform Policy." Obesity Reviews: An Official Journal of the International Association for the Study of Obesity 20 (S2): 90-106.

Kumaraswamy, Mohan M., Florence Y. Y. Ling, Aaron M. Anvuur, and M. Motiar Rahman. 2007. "Targeting Relationally Integrated Teams for Sustainable PPPS." Engineering Construction and Architectural Management 14 (6): 581-96.

Lang, Tim, Geof Rayner, and Elizabeth Kaelin. 2006. "The Food Industry, Diet, Physical Activity and Health: A Review of Reported Commitments and Practice of 25 of the World's Largest Food Companies." City University, London. http://image.guardian.co.uk/sysfiles/Guardian/documents/2006/04/10/foodreportbig25.pdf. 
Lawrence, Mark A., and Phillip I. Baker. 2019. "Ultra-Processed Food and Adverse Health Outcomes." BMJ. https://doi.org/10.1136/bmj.l2289.

Lawther, Wendell C., and Lawrence L. Martin. 2015. Private Financing of Public Transportation Infrastructure: Utilizing Public-Private Partnerships. Lexington Books.

Levine, Ruth, and Danielle Kuczynski. 2009. "Global Nutrition Institutions: Is There an Appetite for Change?," October. https://EconPapers.repec.org/RePEc:ess:wpaper:id:2256.

Liere, Marti J. van, Dessie Tarlton, Ravi Menon, M. Yellamanda, and letje Reerink. 2017. "Harnessing Private Sector Expertise to Improve Complementary Feeding within a Regulatory Framework: Where Is the Evidence?" Maternal \& Child Nutrition 13 Suppl 2 (October). https://doi.org/10.1111/mcn.12429.

Liew, Hui-Peng. 2018. "Soda Consumption and Obesity." Health Behavior and Policy Review. https://doi.org/10.14485/hbpr.5.5.4.

Ludwig, D. S., K. E. Peterson, and S. L. Gortmaker. 2001. "Relation between Consumption of Sugar-Sweetened Drinks and Childhood Obesity: A Prospective, Observational Analysis." The Lancet 357 (9255): 505-8.

Ludwig, David S., and Marion Nestle. 2008. "Can the Food Industry Play a Constructive Role in the Obesity Epidemic?" JAMA: The Journal of the American Medical Association 300 (15): 1808-11.

Malik, Vasanti S., Barry M. Popkin, George A. Bray, Jean-Pierre Després, Walter C. Willett, and Frank B. Hu. 2010. "Sugar-Sweetened Beverages and Risk of Metabolic Syndrome and Type 2 Diabetes: A Meta-Analysis." Diabetes Care 33 (11): 2477-83.

Malik, Vasanti S., Walter C. Willett, and Frank B. Hu. 2013. "Global Obesity: Trends, Risk Factors and Policy Implications." Nature Reviews. Endocrinology 9 (1): 13-27.

Marks, Jonathan H. 2014. "Toward a Systemic Ethics of Public-Private Partnerships Related to Food and Health." Kennedy Institute of Ethics Journal 24 (3): 267-99.

Mendel, Stuart C., and Jeffrey L. Brudney. 2012. "Putting the NP in PPP: The Role of Nonprofit Organizations in Public-Private Partnerships." Public Performance \& Management Review 35 (4): 617-42.

Mitchell, Marc. 2008. "An Overview of Public Private Partnerships in Health." International Health Systems Program Publication, Harvard School of Public Health.

http://aeiglobal.com/PDFs/Public-Private-Partnership-Overview.pdf.

Monteiro, C. A., J-C Moubarac, G. Cannon, S. W. Ng, and B. Popkin. 2013. “Ultra-Processed Products Are Becoming Dominant in the Global Food System." Obesity Reviews: An Official Journal of the International Association for the Study of Obesity 14 Suppl 2 (November): 2128.

Monteiro, Carlos A., and Geoffrey Cannon. 2012. "The Impact of Transnational 'Big Food' Companies on the South: A View from Brazil." PLoS Medicine 9 (7): e1001252.

Monteiro, Carlos A., J-C Moubarac, Geoffrey Cannon, Shu Wen Ng, and Barry Popkin. 2013. "Ultra-Processed Products Are Becoming Dominant in the Global Food System." Obesity Reviews: An Official Journal of the International Association for the Study of Obesity 14: 2128.

Mozaffarian, Dariush, Sonia Y. Angell, Tim Lang, and Juan A. Rivera. 2018. "Role of Government Policy in Nutrition-Barriers to and Opportunities for Healthier Eating." 
Mozaffarian, Dariush. 2017. "Conflict of Interest and the Role of the Food Industry in Nutrition Research." JAMA: The Journal of the American Medical Association 317 (17): 175556.

Nestle, Marion. 2013. Food Politics: How the Food Industry Influences Nutrition and Health. University of California Press.

Nwuneli, Ndidi; Robinson, Ewan; Humphrey, John \& Henson, Spencer. (2014). The role of business in providing nutrient-rich foods for the poor: Two case studies in Nigeria. IDS Evidence Report No. 65. Brighton, UK: IDS, 2014.

OECD 2016. https://www.oecd.org/dac/peer-reviews/Inventory-1-Private-SectorEngagement-Terminology-and-Typology.pdf

Parsons K, Hawkes C, Wells R. Brief 2. What is the food system? A Food policy perspective. In: Rethinking Food Policy: A Fresh Approach to Policy and Practice. London: Centre for Food Policy; 2019.

Pelto, Gretel H., and Jeffrey R. Backstrand. 2003. "Interrelationships between Power-Related and Belief-Related Factors Determine Nutrition in Populations." The Journal of Nutrition 133 (1): $297 \mathrm{~S}-300 \mathrm{~S}$.

Ponnusamy, K., and Others. 2013. "Impact of Public Private Partnership in Agriculture: A Review." Indian Journal of Agricultural Sciences 83 (8): 803-8.

Popkin, Barry M., Linda S. Adair, and Shu Wen Ng. 2012. "Global Nutrition Transition and the Pandemic of Obesity in Developing Countries." Nutrition Reviews 70 (1): 3-21.

Ralston R, Hill SE, Gomes FD, Collin J. Towards preventing and managing conflict of interest in nutrition policy? an analysis of submissions to a consultation on a draft WHO tool. International Journal of Health Policy and Management. 2020 Apr 21.

Reich, Michael R., and Yarlini Balarajan. 2012. "Political Economy Analysis for Food and Nutrition Security." https://openknowledge.worldbank.org/handle/10986/13569.

Roehrich, Jens K., Michael A. Lewis, and Gerard George. 2014. "Are Public-private Partnerships a Healthy Option? A Systematic Literature Review." Social Science \& Medicine. https://doi.org/10.1016/j.socscimed.2014.03.037.

Rowe, Sylvia, Nick Alexander, Alison Kretser, Robert Steele, Molly Kretsch, Rhona Applebaum, Fergus Clydesdale, et al. 2013. "Principles for Building Public-Private Partnerships to Benefit Food Safety, Nutrition, and Health Research." Nutrition Reviews 71 (10): 682-91.

Ruckert, Arne, and Ronald Labonté. 2014. "Public-private Partnerships (ppps) in Global Health: The Good, the Bad and the Ugly." Third World Quarterly 35 (9): 1598-1614.

Sacks, G., B. Swinburn, V. Kraak, S. Downs, C. Walker, S. Barquera, S. Friel, et al. 2013. "A Proposed Approach to Monitor Private-Sector Policies and Practices Related to Food Environments, Obesity and Non-Communicable Disease Prevention." Obesity Reviews: An Official Journal of the International Association for the Study of Obesity 14 Suppl 1 (October): 38-48.

Sacks, Gary, Lana Vanderlee, Ella Robinson, Stefanie Vandevijvere, Adrian J. Cameron, Cliona Ni Mhurchu, Amanda Lee, et al. 2019. "BIA-Obesity (Business Impact Assessment_Obesity and Population-Level Nutrition): A Tool and Process to Assess Food Company Policies and Commitments Related to Obesity Prevention and Population Nutrition at the National Level." Obesity Reviews: An Official Journal of the International Association for the Study of Obesity 20: 78-89. 
Save the Children references should be cited in your reference section (Business Fights Poverty, 2017)

Save the Children, 2018. Don't push it. Why the formula milk industry must clean up its act. http://bit.ly/2FSyfUz

Scott, Peter. 2017. "Global Panel on Agriculture and Food Systems for Nutrition: Food Systems and Diets: Facing the Challenges of the 21st Century." Food Security. https://doi.org/10.1007/s12571-017-0678-y.

Scrinis, Gyorgy. 2016. "Reformulation, Fortification and Functionalization: Big Food Corporations' Nutritional Engineering and Marketing Strategies." The Journal of Peasant Studies 43 (1): 17-37.

Smith, Lisa C., and Lawrence Haddad. 2015. "Reducing Child Undernutrition: Past Drivers and Priorities for the Post-MDG Era." World Development 68 (April): 180-204.

Sodano, V. 2006. "A Power-Based Approach to the Analysis of the Food System." International Agri-Food Chains and Networks, 199-215.

Spielman, David J., Frank Hartwich, and Klaus Grebmer. 2010. "Public--Private Partnerships and Developing-Country Agriculture: Evidence from the International Agricultural Research System." Public Administration and Development: A Journal of the Royal Institute of Public Administration 30 (4): 261-76.

Stevenson, Michael A. 2015. "The Relevance of the Public-private Partnership Paradigm to the Prevention of Diet-Associated Non-Communicable Diseases in Wealthy Countries." Global Public Health 10 (8): 930-46.

Swinburn, Boyd A., Vivica I. Kraak, Steven Allender, Vincent J. Atkins, Phillip I. Baker, Jessica R. Bogard, Hannah Brinsden, et al. 2019. "The Global Syndemic of Obesity, Undernutrition, and Climate Change: The Lancet Commission Report." The Lancet 393 (10173): 791-846.

Swinburn, Vivica Kraak, Harry Rutter, Stefanie Vandevijvere, Tim Lobstein, Gary Sacks, Fabio Gomes, Tim Marsh, and Roger Magnusson. 2015. "Strengthening of Accountability Systems to Create Healthy Food Environments and Reduce Global Obesity." The Lancet 385 (9986): 2534-45.

Thompson, Paul. 2017. "And Don't Forget Food Ethics." The American Journal of Bioethics: AJOB.

Thow, Anne Marie, and Benn McGrady. 2014. "Protecting Policy Space for Public Health Nutrition in an Era of International Investment Agreements." Bulletin of the World Health Organization 92 (2): 139-45.

Wansink, Brian, and Mike Huckabee. 2005. "De-Marketing Obesity." California Management Review 47 (4): 6-18.

Webb, Patrick, Hanqi Luo, and Ugo Gentilini. 2015. "Measuring Multiple Facets of Malnutrition Simultaneously: The Missing Link in Setting Nutrition Targets and Policymaking." Food Security 7 (3): 479-92.

Webster, Mike, and Kevin Sansom. 1999. "Public-Private Partnership and." https://www.ircwash.org/sites/default/files/Webster-1999-Public.pdf.

Willett, Walter, Johan Rockström, Brent Loken, Marco Springmann, Tim Lang, Sonja Vermeulen, Tara Garnett, et al. 2019. "Food in the Anthropocene: The EAT-Lancet Commission on Healthy Diets from Sustainable Food Systems." The Lancet 393 (10170): 44792. 
Wolfensohn, J. D. 1998. "Partnership for Development: Proposed Actions for the World Bank." Washington: The World Bank.

World Health Organization Executive Board. Safeguarding against possible conflicts of interest in nutrition programmes: draft approach for the prevention and management of conflicts of interest in the policy development and implementation of nutrition programmes at country level: report by the Director-General. Executive Board. 142nd session. World Health Organization, 2018. https://apps.who.int/iris/handle/10665/274165

World Health Organization. 2011. "Public-Private Partnerships for Health." http://www.who.int/trade/glossary/ story077/en/index.html (accessed March 2019).

World Health Organization (WHO). Safeguarding Against Possible Conflicts of Interest in Nutrition Programmes. Draft approach for the prevention and management of conflicts of interest in the policy development and implementation of nutrition programmes at country level: Proposed Decision-Making Process and Tool. Geneva: WHO; 2017.

https://www.who.int/nutrition/consultation-doi/nutrition-tool-1stversion. pdf?ua=1. 22.

Yach, Derek, Mehmood Khan, Dondeena Bradley, Rob Hargrove, Stephen Kehoe, and George Mensah. 2010. "ReviewThe Role and Challenges of the Food Industry in Addressing Chronic Disease." Globalization and Health 6: 10.

Yach, Derek. 2008a. "Food Companies and Nutrition for Better Health." Public Health Nutrition 11 (2): 109-11.

Zhang Xueqing. 2005. "Critical Success Factors for Public-Private Partnerships in Infrastructure Development." Journal of Construction Engineering and Management 131 (1): 3-14. 


\section{ANNEXES}

\section{APPENDIX 1: CASE STUDIES}

- Improving nutrition, improving lives

- Grameen Danone Foods Ltd

- Gavi, the Vaccine Alliance

- Micronutrient powder distribution in Bangladesh

- SUN Movement

- Cargill-CARE

- KOKOPlus

- Action Meal

- United for Healthier Kids

APPENDIX 2: INTERVIEW GUIDE 


\section{APPENDIX 1: CASE STUDIES}

\section{IMPROVING NUTRITION, IMPROVING LIVES}

Primary partners: Royal DSM (DSM) and the UN World Food Programme (WFP).

Objective: Improving the nutrient intake of children under 5 years of age and pregnant and lactating women in target populations served by WFP's programmes. The partnership was established in 2007, and by 2013 it had achieved its target of fortified food products reaching $80 \%$ of its beneficiaries. They have since extended their partnership through to 2021, with an increased focus on nutrition awareness-building and the development of new solutions including fortified rice.

Structure and management: The partnership is jointly managed through a steering committee and a management team. Through a joint ownership model, each project under the partnership is co-lead by two project managers, one from each organisation.

Furthermore, DSM encourages employee engagement in the project across various relevant divisions and in some instances embeds employees in WFP for fixed periods to provide technical support and better understand the work of WFP. The partnership also dedicates some funding for WFP to hire technical experts.

Conflict of interest: The partners have committed to separate the philanthropic aims of this partnership from the business objectives of DSM. In addition, they agree to joint responsibility for management, communications, and advocacy for the partnership. The business-to-business model employed by DSM means the nutritional products are provided to intermediary businesses or organisations and therefore do not serve as a DSM marketing vehicle to the end-user. Also, as WFP is moving towards uniform packaging for all its interventions, supplier logos are not included in the final product. The partnership therefore avoids potential tensions around co-branding and cause marketing.

Monitoring and evaluation: WFP evaluated the efficacy of the product formulations and measures the overall impact of the intervention.

\section{Key learning points for PPPs:}

Goal alignment - Through a series of Memoranda of Understanding from 2007 to 2018, the partners have jointly identified detailed shared and non-competing objectives. According to R4D 2014, "Both partners dedicated time to understanding each other's organizations, advocated internally to boost awareness and support for the collaboration, and deliberately built common ground."

Leveraging strengths of each partner - The partnership connects DSM's technical and scientific expertise and WFP understanding of beneficiary needs, local networks, food value chain, and field operational structure.

Adequate financial and non-financial resourcing - The partners committed a combination of financial, product and service contributions.

Commitment from senior management - Support for the partnership extends from the top of both organisations, through to the managerial and operational level.

\section{Sources:}

Bahl, Kanika; Jayaram, Shubha; Brown, Benjamin. (2014). DSM-WFP: A Partnership to Advance the Global Nutrition Agenda. Washington, D.C.: Results for Development, 2014. 
DSM and WFP extend their partnership to tackle malnutrition (09/10/18) https://www.dsm.com/corporate/media/informationcenter-news/2018/10/2018-10-09-dsmand-wfp-extend-their-partnership-to-tackle-malnutrition.html (Accessed 12/09/19)

Eggersdorfer, Manfred \& Bird, Julia. (2016). How to Achieve Transparency in Public-Private Partnerships Engaged in Hunger and Malnutrition Reduction. 10.1159/000442109.

\section{GRAMEEN DANONE FOODS LTD}

Primary partners: Grameen Bank Bangladesh (Grameen) and Groupe Danone (Danone), with support from GAIN, BASF SE, CAPEX, and CARE

Objective: Improved nutrition and livelihoods in target populations through the production and distribution of fortified yogurt ('Shokti Doi') and the engagement of a network of rural saleswomen.

Structure and management: A joint venture established in 2006 as a social enterprise (rather than a conventional PPP, as Grameen is an NGO and not a public-sector organisation), with formal contractual agreements.

Conflict of interest: The ATNI 2018 Global Report scorecard for Danone states that $41 \%$ of its total sales in the seven countries assessed (not including Bangladesh) are from healthy products. The Index also commends the company's marketing commitments and states that it "has not made an explicit commitment to developing and delivering marketing strategies appropriate to reaching under-nourished populations in developing countries" (ATNI 2018).It is unclear from the literature what conflicts of interest may exist or have existed between the partners during the course of the partnership.

Monitoring and evaluation: An external evaluation of the efficacy of Danone's fortified yogurt in a randomised double-blind controlled trial amongst school children was conducted by Johns Hopkins University, with funding from GAIN.

\section{Key learning points for PPPs:}

Leveraging the strengths of partners - Grameen's extensive local rural network through its microfinance programmes and its emphasis on female financial empowerment; Danone's established dairy product expertise; GAIN's fortification programming expertise; BASF SE's nutrient inputs; CAPEX's packaging materials; and CARE's network of rural salespeople.

Goal alignment - despite varying organisational mandates, the partners had alignment on the objective of their partnership.

Understanding beneficiary behaviours - whilst the identification of appropriate partners and alignment of objectives were established, the group did not adequately take into consideration the socio-economic context of this intervention. There was initial dissonance in the business model due to:

- below-market pricing to rural consumers

- $\quad$ supply chain challenges - a lack of refrigeration; saleswomen counting this income source as supplemental rather than primary, and therefore having a low incentive to increase sales

- $\quad$ rural market demand - a cultural tendency toward home-made yogurt

Course-correction - As a result of recurrent losses, the partners modified the business model, with prices being increased to retail market rates, sales being focused on urban centres, and a discontinuation of the rural saleswoman network model.

\section{Sources:}


ATNI. (2018). Global Index 2018: Danone. Utrecht, Netherlands. ATNI Foundation, 2018. https://accesstonutrition.org/index/global-index-2018/scorecards/danone/ (Accessed 07/05/20)

Garrette, Bernard \& Karnani, Aneel. (2010) 'Challenges in Marketing Socially Useful Goods to the Poor', California Management Review, 52 (4), pp. 29-47. doi: 10.1525/cmr.2010.52.4.29.

Hoddinott, John; Gillespie, Stuart; Yosef, Sivan. (2015). Public-Private partnerships and the reduction of undernutrition in developing countries. IFPRI Discussion Paper 01487, December 2015.

Rodrigues, Jonathan \& Baker, Gregory A. (2012). Grameen Danone Foods Limited. International Food and Agribusiness Management Review, 15, 1. 127-158.

Sazawal, Sunil; Habib, Ahsan; Dhingra, Usha; Dutta, Arup; Dhingra, Pratibha; Sarkar, Archana; Deb, Saikt; Alam, Jahangir; Husna, Asmaul \& Black, Robert E. (2013). Impact of micronutrient fortification of yoghurt on micronutrient status markers and growth - a randomized doubleblind controlled trial amongst school children in Bangladesh. BMC public health, 13, 514. https://doi.org/10.1186/1471-2458-13-514

\section{GAVI, THE VACCINE ALLIANCE}

Primary partners: Governments (selected developing and donor countries, in equal numbers), the vaccine industry (one representative each from developing and developed countries), multilateral organisations (UNICEF, WHO, WB), research and technical organisations, civil society organisations, private philanthropy (e.g. BMFG), independent individuals, and the Gavi CEO.

Objective: To increase access to immunisation through new and underused vaccines in developing countries

Structure and management: Gavi is centrally managed by a secretariat in Geneva. Rather than having individual country presence, Gavi works through implementing partners such as WHO in advising country health ministries and with civil society organisations to extend delivery networks. Through diverse funding sources, Gavi provides UNICEF with funding for vaccine procurement. For their part, pharmaceutical companies provide funding, supplies, low-cost vaccines, and participate in innovative financing, with key advice on the latter provided by the World Bank.

Conflict of Interest: At the board level, the International Federation of Pharmaceutical Manufacturers \& Associations and the Developing Countries Vaccine Manufacturing Network have one seat each on the 28-member Gavi board. In addition, all parties, including the private-sector entities, are required to adhere to a detailed Conflict of Interest policy.

Monitoring and evaluation: Gavi's M\&E Framework 2016-2020 includes routine monitoring of performance against strategic targets, KPIs for the Alliance as a whole, Partners' Engagement Framework Performance, and Secretariat and Country Performance. Independent evaluations are also conducted at the country and alliance levels, commissioned by the secretariat and covering grants, programme strategies, and policies, as evaluated against the Gavi Evaluation Policy and reviewed by an Evaluation Advisory Committee.

\section{Key learning points for PPPs:}

Focal issue - Vaccine access differs from food access: vaccines are normally accessed through the healthcare system, with government oversight, whilst consumers access food through diverse sources, in a market dominated by the private sector. Also, whilst vaccines are fundamentally a form of preventative healthcare, not all foods are. However, Gavi offers an example of how public health outcomes are improved through increased, albeit focused and highly managed, collaboration between public and private interests. 
Business model - Gavi uses demand-side incentives to get pharmaceutical companies on board. It is possible that governments, through PPPs, could similarly influence the food market by incentivising more nutritious food production through 1) subsidies, cash transfers and vouchers for nutritious foods and 2) providing tax breaks to companies that produce nutritious foods (GAIN \& USCIB 2018).

Gavi's system of agreeing to purchase vaccines from the private sector at a fixed price has been criticised for providing a disincentive for companies to continually reduce their production costs (Stevenson 2015). There could, however, be ways in which a PPP could continually press companies to remain competitive and effective, passing some efficiencies on to the end user whilst maintaining profits.

Governance - Gavi's multi-stakeholder partnership approach allows for greater oversight and management of potential conflicts of interest, where the involvement of diverse partner types (donors, governments, multilaterals, companies, research, and civil society) encourages transparency and a system of checks and balances designed to redress conflicts of interest whilst leveraging the strengths of each partner.

\section{Sources:}

GAIN \& The USCIB Foundation. (2018). No more missed opportunities: Advancing publicprivate partnerships to achieve global nutrition goals. Geneva, Switzerland: GAIN, 2018.

GAVI. n.d. (Accessed 06/06/2019):

https://www.gavi.org/about/partners/the-partnership-model/

https://www.gavi.org/about/governance/gavi-board/composition/

https://www.gavi.org/library/gavi-documents/

\section{MICRONUTRIENT POWDER DISTRIBUTION IN BANGLADESH}

Primary partners: BRAC, GAIN, and Renata Ltd (a pharmaceutical company with a focus on public health and poverty alleviation in Bangladesh)

Objective: Development, marketing, and sale (through retail and institutional delivery channels) of low-cost micronutrient powder sachets (Pushtikona) targeted for use in complementary foods for children aged 6-24 months in low-income rural households.

Structure and management: GAIN initiated the partnership with the aim of creating a sustainable business solution for reducing micronutrient deficiencies in rural Bangladesh. The partners worked with a network of community health worker,s who received a commission from the sales made. From the literature, the contract modality and governance structure for this PPP is unclear.

Conflict of interest: GAIN and BRAC both have publicly available institutional policies governing their respective engagement with the private sector (GAIN, 2019). However, the existence or management of conflicts of interest between the partners are not indicated in the literature.

Monitoring and evaluation: Sachet retail sales and distribution were tracked by the partners. An evaluation of an intensive intervention combining Pushtikona distribution with a complementary feeding programme by Alive \& Thrive was conducted by IFPRI (IFPRI 2013). A separate small-scale evaluation was also conducted in one sub-district where this intensive intervention was being carried out.

\section{Key learning points for PPPs:}

Leveraging the strengths of each partner - The marketing and demand creation element of the partnership was strengthened by Renata's experience in local advertising campaigns and 
BRAC's interpersonal behaviour change communication expertise. GAIN provided technical expertise and start-up funding to support this.

Combining the networks of each partner - The sales strategy of the partnership linked Renata's network, which extends to $90 \%$ of pharmacies in the country, with BRAC's over 75,000 community health volunteer network, for which GAIN provided product-specific training funding.

\section{Sources:}

Angdembe, Mirak Raj; Choudhury, Nuzhat; Raisul Haque, Mohammad; Ahmed, Tahmeed. (2012). Adherence to multiple micronutrient powder amongst young children in rural Bangladesh: a cross-sectional study. BMC public health, 15, 440. https://doi.org/10.1186/s12889-015-1752-z

GAIN. (2014). A Child's Daily Nutrition within a Small Sachet. Geneva: GAIN. www.gainhealth.org/wp-content/uploads/2014/04/63.-Case-Story.-A-childsdaily-nutritionwithin-a-small-sachet.-Micronutrient-Powders-in-Bangladesh.pdf

GAIN. (2019). Principles of Engagement. Geneva, GAIN.

https://www.gainhealth.org/sites/default/files/policies/gain-principles-of-engagement.pdf (Accessed 07/05/20)

Hoddinott, John; Gillespie, Stuart; Yosef, Sivan. (2015). Public-Private partnerships and the reduction of undernutrition in developing countries. IFPRI Discussion Paper 01487, December 2015.

International Food Policy Research Institute. (2013). Alive \& Thrive Preliminary Process Evaluation Report. Dhaka, Bangladesh: IFPRI.

\section{SUN MOVEMENT}

Primary partners: A coalition consisting of country, business, civil society, donor, and UN networks

Objective: To achieve a world free from malnutrition in all its forms by 2030 by facilitating collective action through: strengthening the enabling political environment; prioritising and implementing nutrition actions; and leveraging financial resources for nutrition.

Structure and management: This coalition of self-organised networks is led the country level by SUN Government Focal Points and at the global level by a SUN Movement Coordinator, Lead Group, and Executive Committee. Four SUN networks - business, civil society, donor, and UN - are supported by network facilitators and their secretariats. The administrative and operational management of the overall movement is supported by a secretariat.

Conflict of interest: Principles of Engagement have been established to guide multistakeholder collaboration; amongst other values, these encourage mutual accountability and acting with integrity and in an ethical manner. One aim of the movement is to strengthen the capacity for cross-sector collaboration by 2020, "ensuring that countries develop an approach to preventing and managing conflicts of interest as they emerge" (SUN n.d.). This is being carried out through information dissemination, the development of an ethical framework, and the setup of a working group to discuss and share ideas on conflicts of interest. A reference note and toolkit, developed by an independent organisation (Global Social Observatory), provides guidance on defining, preventing, identifying, managing, and monitoring conflicts of interest.

Monitoring and evaluation: SUN assesses progress towards its objectives using a Monitoring, Evaluation, Accountability and Learning (MEAL) system. A set of country dashboards provide a standardised set of indicators covering the various domains of the 
movement's theory of change. Additional indicators may be added to this set as required and where data is available, and the dashboard can be adapted to the sub-national level. A comprehensive baseline MEAL report was produced to enable the movement to track progress on its 2016-2020 Strategic Roadmap. An Independent Comprehensive Evaluation of the movement was also conducted in 2014 to assess its progress and ability to deliver on its objectives and to inform its 2016-2020 Strategic Roadmap.

\section{Key learning points for PPPs:}

Tracking progress - the movement has both a complex ongoing internal mechanism and occasional external reviews of its progress on its theory of change on national and global levels.

Developing fit-for-purpose resources and tools to manage conflicts of interest - The SUN movement enlisted the support of a third party to provide guidance to members for managing conflicts of interest.

Knowledge sharing - the movement publicly shares tools, guidance, evaluation results and relevant country level data, offering resources for its members, and other countries/organisations.

\section{Sources:}

Global Social Observatory. (2015). Engaging in the SUN Movement: Preventing and managing conflicts of interest. Reference note and toolkit. Geneva, Switzerland: GSO, 2015. https://scalingupnutrition.org/wp-content/uploads/2014/05/Reference-Note-and-ToolkitEnglish.pdf (Accessed 10/09/19)

SUN Strategy \& Roadmap 2016-2020. https://scalingupnutrition.org/wpcontent/uploads/2016/09/SR_20160901_ENG_web_pages.pdf (Accessed 10/09/19)

SUN. n.d. Monitoring, evaluation, accountability and learning.

https://scalingupnutrition.org/progress-impact/monitoring-evaluation-accountability-andlearning-meal/ (Accessed 10/09/19)

SUN. n.d. Preventing and managing conflict of interest. https://scalingupnutrition.org/sharelearn/multistakeholder-engagement/preventing-and-managing-conflicts-of-interest/

\section{CARGILL-CARE}

Primary partners: Cargill and CARE, with local government and institutions

Objective: To improve the lives of rural agricultural communities through projects that support increased productivity and incomes for small-scale farmers, climate change resilience, female empowerment, and better nutrition. Focal countries include Brazil, Costa Rica, Cote D'Ivoire, Egypt, Ghana, Guatemala, Honduras, Nicaragua, India, and Indonesia.

Structure and management: The partnership originated as a decades-long philanthropic relationship and evolved into a strategic engagement from 2008. This engagement has completed three phases thus far: 2008-2013; 2013-2016; and 2016-2019. Cargill leads on resourcing agreed projects through funding, capacity, and technical know-how, whilst CARE designs, implements, monitors, and evaluates them. Whilst CARE is the implementation partner, the majority of projects also include the participation of Cargill employee volunteers. Further details of how this partnership is structured and managed internally are unclear from the literature.

Conflict of interest: Details of how conflicts of interest are managed within this partnership are unclear from the literature. 
Monitoring and evaluation: CARE conducts the monitoring and evaluation of all projects under this partnership.

\section{Key learning points for PPPs:}

Goal alignment and articulated individual motivations - Cargill seeks to invest in the communities where it operates, and CARE seeks to deliver on its organisational goal of defeating poverty and elevating human dignity. According to the report A Decade of Impact 2018, published by CARE, both organisations have "common core values and culture."

Measuring progress - the M\&E framework was jointly developed by the partners, which helps to build shared understanding and ownership of what success looks like.

Long-term relationship - the partners found this arrangement to offer greater opportunities for scale and flexibility that a shorter partnership may have provided.

Not all projects need to be sustained - in Brazil, the partnership identified a time-bound programme to collaborate on and, once successfully completed, determined that further resources were more effective being channelled to other countries (BFP n.d.).

\section{Sources:}

Business fights Poverty. N.d. Building transformational partnerships https://businessfightspoverty.org/articles/download-centre-151-register/ (Accessed 08/09/2019)

Cargill and CARE. 2018. A Decade of Impact: CARE-Cargill Partnership. https://www.cargill.com/doc/1432128050867/cargill-care-a-decade-of-impact-report-pdf.pdf (Accessed 08/09/2019)

New Ways of Partnering: The CARE and Cargill Partnership. 02/12/19. https://businessfightspoverty.org/articles/new-ways-of-partnering-the-care-and-cargillpartnership/ (Accessed 08/09/2019)

\section{KOKOPLUS}

Primary partners: Ajinomoto, Ghana Health Service, CARE, Women's Employment Support, and WFP

Objective: Reduce stunting in Ghana through the sale of a low-cost fortified complementary food supplement and establish a self-sustaining social business model.

Structure and management: Details of how this partnership is structured and managed internally are unclear from the literature.

Conflict of interest: An estimated 17\% of Ajinomoto's total sales is derived from healthy products. However, it has stated targets for the development of fortified food products for reducing malnutrition in developing countries, and its non-commercial approach to addressing undernutrition in developing countries is assessed by ATNI to be "robust and of a long-term nature" (ATNI 2018). This being said, details of how conflicts of interest are managed within the KOKOPLUS partnership are unclear from the literature.

Some efficacy studies, such as Gosh et al. 2017 and Tanoh-Debrah et al. 2019, are respectively partially and fully funded by Ajinomoto. It is unclear how this conflict of interest was managed or mitigated with respect to the research design or interpretation of the studies.

Monitoring and evaluation: A case study on this partnership on the Nutrition Connect website lists 10 journal articles on the impact of KOKOPLUS. Amongst the literature are evaluations of the product's nutritional impact, shelf life, and distribution mechanisms (market-based versus accompanied by demand creation and behaviour change 
communication activities), as well as of the nutritional value of the pre- and post-fortified product.

\section{Key learning points for PPPs:}

Build upon an existing local food - A recognised and widely used complementary food (koko, a fermented porridge) was fortified, rather than developing a completely new product for the market.

Work through local channels - The product's development, production, and outreach are conducted by Ghanaians, such as village-based entrepreneurs and local health workers.

\section{Sources:}

ATNI. (2018). Global Index 2018: Ajinomoto. Utrecht, Netherlands. ATNI Foundation, 2018. https://accesstonutrition.org/index/global-index-2018/scorecards/ajinomoto/ (Accessed 07/05/20)

GAIN. (n.d.). Ghana Nutrition Improvement Project. https://nutritionconnect.org/resourcecenter/ghana-nutrition-improvement-project (Accessed 07/05/20)

Ghosh, Shibani; Strutt, Nicholas; Otoo, Gloria E; Suri, Devika J; Ankrah, Judith; Johnson, Thomas; Nsiah, Paul; Furuta, Chie; Murakami, Hitoshi; Perera, Gillian; Kwan Ho Chui,Kenneth; Bomfeh, Kennedy; Amoono Kuofi, Harold; Tano Debrah, Kwaku \& Uauy, Ricardo. (2017). Effect of the provision of a macro- and micro-nutrient fortified complementary food supplement on nutritional status of Ghanaian infants. The FASEB Journal 2017 31:1_supplement, 43(1).

J. Aaron, Grant; Strutt, Nicholas; Boateng, Nathaniel Amoh; Guevarra, Ernest; Siling, Katja; Norris, Alison; Ghosh, Shibani; Nyamikeh, Mercy; Attiogbe, Antoine; Burns, Richard; Foriwa, Esi; Toride, Yasuhiko; Kitamura, Satoshi; Tano-Debrah, Kwaku; Sarpong, Daniel \& Myatt, Mark. (2016). Assessing Program Coverage of Two Approaches to Distributing a Complementary Feeding Supplement to Infants and Young Children in Ghana. PLoS ONE 11 (10): e0162462.

Suri, Devika J; Tano-Debrah, Kwaku \& Ghosh, Shibani. (2014). Optimization of the nutrient content and protein quality of cereal-legume blends for use as complementary foods in Ghana. Food and Nutrition Bulletin, 35(3), 372-381.

Tano-Debrah, Kwaku \& Saalia, Firibu \& Ghosh, Shibani \& Hara, Masashi. (2019). Development and Sensory Shelf-Life Testing of KOKO Plus: A Food Supplement for Improving the Nutritional Profiles of Traditional Complementary Foods. Food and Nutrition Bulletin. 40. 037957211984829. 10.1177/0379572119848290.

The Ajinomoto Foundation. (n.d). Spotlight on the Ghana Nutrition Improvement Project (GNIP) - "KOKO Plus" http://www.theajinomotofoundation.org/wpcontent/uploads/gana_en.pdf (accessed 08/09/2019).

\section{ACTION MEAL}

Primary partners: Dala Foods Nigeria Ltd and the Institute of Human Virology, Nigeria (IHVN), supported by PEPFAR/USAID

Objective: To locally produce and distribute a vitamin A-fortified cereal mix for women and children with HIV/AIDS in Northern Nigeria (2009-2012).

Structure and management: Details of how this partnership was structured and managed internally are unclear from the literature. However, it is understood that IHVN procured the product through donor funding for free distribution to vulnerable HIV/AIDS patients. 
Conflict of interest: Details of how conflicts of interest were managed in this partnership are unclear from the literature.

Monitoring and evaluation: Details of how this project was evaluated by the funder are unclear from the literature. However, Nwuneli et al (2014) provide an overview of achievements and challenges under this partnership.

\section{Key learning points for PPPs:}

Identifying appropriate partners - Dala Foods were already producing a widely accepted range of products aimed at low-income consumers in Northern Nigeria; IHVN and PEFAR/USAID were seeking to support the recovery of HIV/AIDS patients with severe acute malnutrition in the country.

Sustainable business models need to be considered - Dala Foods had intended to extend Action Meal to become a retail product but were unable to do so for several reasons:

- $\quad$ Large-scale production and high sales volume were needed to make production viable. This required sustained demand, an improved distribution mechanism, and marketing support, which were beyond the capacity of the company without support from partners.

- $\quad$ As the product was originally approved by regulatory authorities for non-profit distribution under IHVN, it was not permitted for retail sales.

- $\quad$ As the registered owner of the product under this agreement was IHVN, Dala Foods may have been required to pay it royalties on retail sales of Action Meal.

\section{Sources:}

Nwuneli, Ndidi; Robinson, Ewan; Humphrey, John \& Henson, Spencer. (2014). The role of business in providing nutrient-rich foods for the poor: Two case studies in Nigeria. IDS Evidence Report No. 65. Brighton, UK: IDS, 2014.

Robinson, Ewan; Nwuneli, Ndidi; Henson, Spencer \& Humphrey, John. (2014). Mapping value chains for nutrient-dense foods in Nigeria. IDS Evidence Report No. 65. Brighton, UK: IDS, 2014.

\section{UNITED FOR HEALTHIER KIDS}

Primary partners: Nestlé, with various national and international public and private sector partners in eight countries and two country groupings. For example, in Mexico these partners included the Ministry of Health, Ministry of Public Education, the Kimberly-Clark Corporation, and Televisa.

Objective: To use social and mass media and integrated social marketing targeted to parents and caregivers for behavioural change to tackle childhood obesity and malnutrition. These channels are complemented by different offline interventions for target populations.

Structure and management: Nestlé convenes a global advisory board to provide advice on the framework and content of the programme. A global set of six behavioural goals for improved nutrition actions have been established, with each country determining the priority goals applicable to their context.

Conflict of interest: The target audience of this programme is parents of children under the age of 12. According to the ATNI 2018 Global Report's company scorecard, only approximately $19 \%$ of Nestlé's sales are derived from healthy products. The report also assesses its policy on marketing to children as "relatively strong" but does not extend to secondary schools or adequately cover areas frequented by children. Furthermore, while the company's policy is in close alignment with The Code, ATNI found it to not be applied to all relevant products or in low-risk countries. Also, the scorecard suggests that the company 
"support unbranded programs to avoid the impression that educational programs are used for marketing purposes" (ATNI 2018).

Details of how conflicts of interest were managed in the United for Healthier Kids partnership are unclear from the literature. However, the project website includes a link to Nestlés overall Corporate Business Principles (Nestlé, 2010) and the related Compliance Reporting System.

Monitoring and evaluation: The reach of this programme is chiefly evaluated through the number of people reached by the messaging, including television audience, social media views and website visits. According the Drewnoski et al. 2018, this data is further assessed by external researchers for objectively measured behaviour change, progress reports are shared with partners and the public, and efficiency and return on investment calculated. Drewnoski also states that evaluations are required to determine whether this type of private-public engagement can make a significant impact on public health, in line with the WHO's guidelines for preventing and managing conflicts of interest.

\section{Key learning points for PPPs:}

Effective use of social media and mass media to target behaviour change - this enables a wide reach in most countries, even outside of urban centres. It enables the mobilisation of a social movement for collective action. The inclusion of a TV network as a partner broadens both the reach and content opportunities for messaging.

Monitoring of progress - the use of media channels to promote messaging enables precise tracking of the project's reach

\section{Sources:}

ATNI. (2018). Global Index 2018: Nestlé. Utrecht, Netherlands. ATNI Foundation, 2018. https://accesstonutrition.org/index/global-index-2018/scorecards/nestle/ (Accessed 07/05/20)

Changing Markets Foundation. (2019). Based on Science? New York, USA: Changing Markets Foundation, 2019. http://changingmarkets.org/wpcontent/uploads/2019/04/Based_on_science_FINAL.pdf

Drewnowski, Adam; Caballero, Benjamin; Das, Jai K; French, Jeff; Prentice, Andrew M; Fries, Lisa R; van Koperen, Tessa M; Klassen-Wigger, Petra \& Rolls, Barbara J. (2018). 'Novel public-private partnerships to address the double burden of malnutrition'. Nutrition Reviews 76 (11), 805-821.

Jacobs, Andrew \& Richtel, Matt. (2017). 'How Big Business Got Brazil Hooked on Junk Food', New York Times, September 16, 2017

https://www.nytimes.com/interactive/2017/09/16/health/brazil-obesity-nestle.html

Nestlé. (2010). The Nestlé Corporate Business Principles. Vevey, Switzerland; Nestec Ltd. 2010 https://www.nestle.com/sites/default/files/assetlibrary/documents/library/documents/corporate governance/corporate-business-principlesen.pdf (Accessed 07/05/20) 


\section{APPENDIX 2: INTERVIEW GUIDE}

Introduction

Thanks again for taking the time to speak with me for our research study. Would it be helpful for me to provide some background on the project before jumping in with questions for you?

I am working, along with my Johns Hopkins colleagues Professors Jessica Fanzo and Jeremy Shiffman, as well as recent masters graduate Shreya Das, on a qualitative research project to better understand the role of Public Private Partnerships (PPPs) in nutrition. The project is funded by GAIN. While it is supported by GAIN, the study is independent and impartial, meaning that we are largely selecting our own key informants and are completely conducting our analysis and interviews independently. We ultimately hope to submit our findings for publication in a peer-review journal.

As I mentioned over email, we are trying to understand:

- $\quad$ Are there too few high-quality or impactful PPPs in nutrition?

- If so, what is inhibiting their development?

- $\quad$ And what can be done to encourage more?

We realise that 'high quality' is up for interpretation but I am hoping that over the course of our discussion to get your insights on how you understand PPPs and what you think makes a high-quality PPP in the nutrition sector. I'd also like to get your insights around three other key areas:

- $\quad$ The first being around the status of PPPs in the nutrition sector: So for example, the extent to which there are quality or effective PPPs in the nutrition sector? And some examples of successful and unsuccessful cases that come to mind.

- $\quad$ The second is around the challenges surrounding what may be holding back more high-quality PPPs in the nutrition sector?

- $\quad$ The third is around potential solutions. So here, l'd like to ask your insights around what might be done to ameliorate challenges you identify and incentivise more innovative and high quality PPPs that stand a good change of advancing nutrition outcomes?

Do you have any questions for me before we begin?

Great, and before we begin, one important note, l'd like to emphasise this interview is completely confidential, meaning your name will not be associated with anything you share with me today, and the only other person who may have access to the notes that I take during our conversation is Jess, Jeremy and Shreya. And so with that, I am wondering if I may have your permission to record our conversation to supplement my note-taking?

\section{Questions}

Status of PPPs: Types, different players, their presence in the nutrition sector

- $\quad$ How would you define PPPs and who are the major stakeholders involved?

- $\quad$ Are there other partnership models in nutrition of importance?

Prevalence of PPPs in Nutrition: To what extent are PPPs prevalence in nutrition?

- $\quad$ Types of PPPs in nutrition - What are the main areas that have the potential to involve the private sector, and types of engagements?

Quality of PPPs:

- $\quad$ Are there too few high-quality ones? 
- If yes, why are there so few? And what factors are unique to private sector engagement in nutrition as opposed to say education and health?

Challenges in PPPs: What is holding back high-quality, effective PPPs

- $\quad$ Could you tell us a bit about the challenges you've faced in the process - around governance policy, or operational challenges?

- What are the biggest barriers?

Solutions for the above issues:

- How have you tried to navigate the above challenges?

- What are the steps one might have taken to incentive private sector engagement, eliminate conflict of interests, resolve disagreements and tensions, and increase consumer demand, accountability?

- What are the key factors that ensure effective PPPs?

- What are the most important factors for success?

Examples:

- $\quad$ Successful Examples, what about them made it successful

- Unsuccessful Examples, what didn't work?

Other Questions:

- $\quad$ From your experience, are there any areas we should be looking at?

- $\quad$ Are there any detrimental PPP examples out there? 